NBER WORKING PAPER SERIES

\title{
WHAT WILL MY ACCOUNT REALLY BE WORTH? AN EXPERIMENT ON EXPONENTIAL GROWTH BIAS AND RETIREMENT SAVING
}

\author{
Gopi Shah Goda \\ Colleen Flaherty Manchester \\ Aaron Sojourner \\ Working Paper 17927 \\ http://www.nber.org/papers/w17927
}

\author{
NATIONAL BUREAU OF ECONOMIC RESEARCH \\ 1050 Massachusetts Avenue \\ Cambridge, MA 02138 \\ March 2012
}

We are grateful to Jackie Singer and Shelly Wymer for their assistance with administering this project. The research reported herein was performed pursuant to a grant from the U.S. Social Security Administration (SSA) funded as part of the Financial Literacy Center. The authors also acknowledge additional support provided by the TIAA-CREF Institute and the University of Minnesota Carlson School of Management. The authors thank John Beshears, Jeff Brown, Wandi Bruine de Bruin, Katherine Carman, James Choi, Courtney Coile, Adeline Delavande, Maria Fitzpatrick, Damon Jones, Amit Kramer, Ron Laschever, Annamaria Lusardi, Erzo F.P. Luttmer, Dayanand Manoli, Olivia Mitchell, Enrico Moretti, Victor Stango, Robert Willis, Joanne Yoong and seminar participants at the University of Illinois and at the University of Chicago for comments. The opinions and conclusions expressed herein are solely those of the authors and do not represent the opinions or policy of SSA, any agency of the Federal Government, the National Bureau of Economic Research, or any other institution with which the authors are affiliated. c2012 Goda, Manchester and Sojourner. All rights reserved.

NBER working papers are circulated for discussion and comment purposes. They have not been peerreviewed or been subject to the review by the NBER Board of Directors that accompanies official NBER publications.

(C) 2012 by Gopi Shah Goda, Colleen Flaherty Manchester, and Aaron Sojourner. All rights reserved. Short sections of text, not to exceed two paragraphs, may be quoted without explicit permission provided that full credit, including $\odot$ notice, is given to the source. 
What Will My Account Really Be Worth? An Experiment on Exponential Growth Bias and Retirement Saving

Gopi Shah Goda, Colleen Flaherty Manchester, and Aaron Sojourner

NBER Working Paper No. 17927

March 2012

JEL No. H3,J14

\begin{abstract}
Recent findings on limited financial literacy and exponential growth bias suggest saving decisions may not be optimal because such decisions require an accurate understanding of how current contributions can translate into income in retirement. This study uses a large-scale field experiment to measure how a low-cost, direct-mail intervention designed to inform subjects about this relationship affects their saving behavior. Using administrative data prior to and following the intervention, we measure its effect on participation and the level of contributions in retirement saving accounts. Those sent income projections along with enrollment information were more likely to change contribution levels and increase annual contributions relative to the control group. Among those who made a change in contribution, the increase in annual contributions was approximately $\$ 1,150$. Results from a follow-up survey corroborate these findings and show heterogeneous effects of the intervention by rational and behavioral factors known to affect saving. Finally, we find evidence of behavioral influences on decision-making in that the assumptions used to generate the projections influence the saving response.
\end{abstract}

Gopi Shah Goda

Stanford University

SIEPR

366 Galvez St.

Stanford, CA 94305

and NBER

gopi@stanford.edu

Colleen Flaherty Manchester

Human Resources and Industrial Relations

University of Minnesota

Room 3-300R

321 - 19th Avenue South

Minneapolis, MN 55455

cmanch@umn.edu

\author{
Aaron Sojourner \\ University of Minnesota \\ Carlson School of Management \\ 321 19th Ave S, 3-300 \\ Minneapolis, MN 55455 \\ asojourn@umn.edu
}




\section{Introduction}

With the shift toward defined contribution (DC) retirement plans, Americans' retirement security increasingly requires individuals to make responsible, informed wealth accumulation decisions over their working years (Hacker 2006; Even and Macpherson 2007; Skinner 2007). Among Americans with pensions, the share with only a traditional defined benefit pension fell from 60 to 10 percent between 1980 and 2003. Over the same period, the share with only a DC plan rose from 17 to 62 percent (Buessing and Soto 2006). Because individuals only have one shot at saving for retirement, the stakes are high and the consequences of suboptimal choices for financial well-being are potentially large.

Economists debate the extent to which Americans save too little, too much, or just the right amount for retirement (Ameriks et al. 2007; Lusardi and Mitchell 2011; De Nardi et al. 2010). In standard models of retirement saving, individuals with low levels of saving are interpreted as responding optimally given a strong taste for present rather than future consumption, anticipation of steep earnings growth, or binding liquidity constraints.

However, a growing body of work raises concerns about how well-equipped individuals are to make optimal saving decisions. They may be cognitively constrained, as evidenced by low rates of financial literacy (Lusardi and Mitchell 2007). Many are affected by behavioral factors outside standard models, such as procrastination or inertia (e.g., Thaler and Benartzi 2004, Choi, Laibson, Madrian and Metrick 2004), default rules (e.g., Madrian and Shea 2001; Beshears, Choi, Laibson and Madrian 2006; Mitchell, Mottola, Utkus and Yamaguchi 2009; Goda and Manchester 2010), peers (e.g., Duflo and Saez 2003), and how information is conveyed or framed (Bernheim, Fradkin and Popov 2011; Choi, Haisley, Kurkoski and Massey 2012).

A key requirement for optimal saving decisions is an accurate understanding of both

University of Chicago for comments. The opinions and conclusions expressed herein are solely those of the authors and do not represent the opinions or policy of SSA, any agency of the Federal Government, or any other institution with which the authors are affiliated. (C)2012 Goda, Manchester and Sojourner. All rights reserved. 
the accumulation of retirement saving contributions to assets at retirement, and the decumulation of assets to income in retirement. Many individuals systematically underestimate the returns to saving that accrue from compound growth (Eisenstein and Hoch 2007; Stango and Zinman 2009). By distorting one's view of intertemporal budget constraints, exponential growth bias could lead to sub-optimal saving decisions.

Past research on exponential growth bias has either used observational data on credit card use to show evidence consistent with its effect (Stango and Zinman 2009), or experiments in labs showing that learning about exponential growth affects the accuracy of subjects' survey responses to hypothetical financial scenarios (Eisenstein and Hoch 2007). There is little evidence on the extent to which exponential growth bias affects retirement saving relative to the standard rational and behavioral factors described above. Nor is there much evidence on whether learning about exponential growth, or financial concepts more generally, affects actual saving decisions.

This study makes several contributions to improving understanding of how exponential growth bias affects retirement saving decisions. First, we show theoretically how exponential growth bias affects both the accumulation and the decumulation phase of retirement saving. While past work on exponential growth bias has focused on the accumulation phase, we construct a simple model of optimal saving behavior where individuals have biases in their perceptions of both phases of retirement saving. We establish new results by showing that exponential growth bias affects the accumulation and decumulation of retirement wealth in the same direction, and that the effect of reducing bias on optimal saving behavior depends on the initial direction of the bias and the elasticity of intertemporal substitution (EIS).

Second, we conduct a large-scale field experiment designed to inform individuals about exponential growth and measure changes in their saving choices, which prior work has not done. Our mail and online intervention provided projections of how contributions today would map into future account balances at retirement and income in retirement. Using administrative data prior to and following the intervention, we measure the effect of our in- 
terventions on contribution levels for discretionary tax-deferred retirement savings accounts by employees at the University of Minnesota. ${ }^{1}$ We find that providing income projections along with general plan information and materials assisting people through the steps of changing contribution rates resulted in a 29 percent higher probability of a change in contributions relative to a control group over a six-month period. In addition, individuals sent this treatment increased their annual contributions by $\$ 85$ more than the control group during the study period. This treatment effect is economically meaningful in that this increase is more than double that experienced by the control group. Because only a small portion of the sample changed contribution levels, the magnitude of the increase among those who made a change was much larger, approximately $\$ 1,150$ dollars per year. Additional features of the experiment yield insights into which components of the treatment generate the observed effects. In particular, our findings suggest that both the provision of retirement planning materials and projections contribute positively to the treatment effect, although there is not strong evidence that either the planning materials or the projections alone induced a significant increase in contributions.

Third, by supplementing administrative records on saving with a follow-up survey administered after the intervention, we have rich data on individual characteristics and behaviors. We utilize responses from the survey to provide corroborative evidence regarding the effectiveness of the intervention by exploring the impact of our interventions on additional aspects of the saving decision-making process. Among survey respondents, those sent full income disclosures were more likely to report having recently engaged in and being more informed about retirement planning, having higher certainty about the amount of income they expect to have in retirement, and greater satisfaction with their overall financial condition relative to the control group. While the fact that the survey respondents are a non-random subsample of the population warrants caution when interpreting these results, these findings

\footnotetext{
${ }^{1}$ In concurrent work, Song (2012) reports findings from an experiment that aimed to educate rural Chinese farmers about exponential growth through home visits and personal financial counseling and which led to increased saving. The two studies differ in sample, setting, and treatment, and the findings are complementary.
} 
reinforce our earlier evidence that the intervention influenced saving decisions and that the results are not driven by chance alone.

Fourth, in light of our theoretical model, our empirical findings contribute new evidence on the EIS, a critical preference parameter in saving decisions. When EIS $<1$, optimal saving would go down in response to an increase in the returns to saving because the income effect is larger than the substitution effect. When EIS $>1$, the substitution effect dominates and optimal saving would rise. Most estimates of the EIS are between zero and one, with more recent evidence providing estimates closer to one (e.g., Engelhardt and Kumar 2009; for review, see Attanasio and Weber (2010) and references therein). If, as the literature suggests, individuals have negative exponential growth bias (Wagenaar and Sagaria 1975; Eisenstein and Hoch 2007; Stango and Zinman 2009), then our finding of a positive effect of the intervention on saving levels implies an EIS greater than 1 in our sample, i.e. the substitution effect dominates on average. This approach answers recent calls to use experimental designs to better understand theoretical parameters (Card, DellaVinga and Malmendier 2011; Charness and Kuhn 2011; List 2011).

Fifth, elements of our study design allow us to evaluate the interaction of this financial education intervention with standard economic and behavioral economic factors. In terms of factors that influence optimal saving decisions, we find that, among survey respondents, individuals who display higher rates of time discounting, as well as those who report tighter liquidity constraints, are significantly less likely to respond to the intervention. Heterogeneity in optimal retirement saving decisions underscores a virtue of policies like this one that provide information rather than subsidizing or mandating particular behaviors.

We also find evidence that behavioral economic factors affect individuals' response to the intervention. We analyze the interaction between measures of time-inconsistent preferences and treatment and find that, among survey respondents, individuals who report a tendency to procrastinate are significantly less likely to respond to the intervention. This finding implies that financial literacy interventions may not be as effective without addressing the behavioral 
forces that may undermine the success of the intervention. In addition, a unique feature of our study design is that we randomize the assumptions used to generate the projections across employees, which allows us to test for framing effects on our outcomes of interest. We find that a higher assumed retirement age has a significant positive impact on the propensity to change one's contribution amount. We also find that both higher assumed retirement ages and higher assumed hypothetical contribution amounts induce larger increases in the level of saving; however, we find no evidence that the assumed rate of investment return affects saving behavior. The results from the follow-up survey indicate no evidence that the assumptions used in the projections affect beliefs regarding one's expected retirement age or expected rates of return. Thus, our evidence suggests that assumptions used in the projections operate through framing, rather than affecting underlying beliefs about the likelihood of future events.

Lastly, our findings are relevant for public policy, employers in general, and financialservice firms in particular. The U.S. Congress is considering the Lifetime Income Disclosure Act (S. 267; HR. 1534), which would require DC plan administrators to annually provide income disclosures that would project the value of a lifetime annuity that a plan participant could purchase at retirement given her current retirement savings. The effects of such a policy have never before been tested. Investment managers and firms offering DC retirement plans want to understand the effects of providing such projections, which can be provided with minimal marginal cost rather than changing the default contribution level which could be costly to firms that offer saving matches. Our findings suggest that on average, individuals save more when provided with information about how current saving translates into income in retirement, suggesting the mapping is not fully understood absent the intervention. The results also suggest that care should be taken in the choice of projection assumptions used, as they may affect outcomes. The heterogeneity in our results implies that among those who display time-inconsistent preferences, high discount rates, or high liquidity constraints, the intervention is unlikely to significantly change saving behavior. 
The remainder of our paper proceeds as follows. We model how the potential for biases in the understanding of exponential growth affect saving decisions in Section 2. Section 3 describes our experimental design, including details regarding our treatment groups and randomization procedure, and Section 4 explains our analytic approach. Section 5 presents and discusses results on the effect of the intervention on saving behavior, the saving process, and heterogeneous effects of the intervention. Section 6 concludes the paper.

\section{Model of Saving Decision Under Exponential Growth Bias}

Exponential growth (EG) bias distorts understanding of both the accumulation and decumulation phases of retirement planning. We develop a simple model of how EG bias affects subjective understanding of the intertemporal budget constraint and, consequently, optimal saving choices. The effect of EG bias on the accumulation phase of retirement saving is intuitive. If the power of EG is underestimated, then potential returns to retirement saving are under-appreciated. How EG bias affects the decumulation phase is more subtle but operates in the same direction. We show that reducing EG bias would have an ambiguous effect on optimal saving, with a sign that depends on both the initial direction of the bias and the elasticity of intertemporal substitution (EIS).

We consider a simple two-period model in which a worker must decide how much to consume now versus how much to save for future retirement. Our model differs from a standard intertemporal budgeting model in allowing people to misperceive the functions by which assets accumulate leading up to retirement and by which assets at retirement decumulate into retirement income. We parameterize EG bias by $\theta>0$ (Wagenaar and Sagaria 1975; Eisenstein and Hoch 2007; Stango and Zinman 2009). The perception is unbiased if $\theta=1$, negatively biased if $\theta<1$, and positively biased if $\theta>1$.

Given current wealth $A_{1}$, current income $Y_{1}$, and degenerate beliefs about the number of 
years of accumulation before retirement $(K)$, the subjective saving problem is to choose $A_{2}$ to maximize:

$$
U\left(C_{1}\right)+\beta^{K} U\left(C_{2}\right)
$$

subject to:

$$
\begin{aligned}
A_{2}+C_{1} & =Y_{1}+A_{1} \\
C_{2} & =f\left(A_{2} ; K, \theta\right)
\end{aligned}
$$

where $f\left(A_{2} ; K, \theta\right)$ represents the subjective mapping from today's saving choice to perceived retirement income given years until retirement $K$ and EG bias $\theta$.

We separately analyze the effect of $\theta$ on the perception of the accumulation and decumulation phases of retirement planning and examine how changing $\theta$ would impact optimal saving. ${ }^{2}$ EG bias distorts understanding of the accumulation phase in a straightforward way. Given degenerate beliefs about the rate of return $\left(R_{a}\right)$ during accumulation, assume that an individual with EG bias $\theta$ believes $A_{2}$ will generate retirement balance $B_{\theta} \equiv R_{a}^{K \theta} A_{2}$. Those with negative EG bias underestimate the returns to saving and have an overly-pessimistic view of its payoff during accumulation.

EG bias also impacts perception of the decumulation phase. The analysis here is novel, more subtle, and connects to how EG bias affects borrowing decisions (Stango and Zinman 2009). To illustrate the impact of EG bias on decumulation in a tractable, intuitive way, consider how EG bias affects perception of the fixed retirement income stream $(I)$ over a given number of years $(T)$ that can be purchased with retirement asset balance $B$. Assuming assets earn gross rate of return $R_{d}>1$, perceived income $\left(I_{\theta}\right)$ would be determined implicitly by:

$$
B=I_{\theta}\left(\frac{1}{R_{d}^{\theta}}+\frac{1}{R_{d}^{2 \theta}}+\ldots+\frac{1}{R_{d}^{T \theta}}\right) .
$$

This implies a perceived flow price (or annuity price), $p_{\theta} \equiv \frac{I_{\theta}}{B}$. To index the bias in

\footnotetext{
${ }^{2}$ Adding more periods or uncertainty to the model add complexity but do not change the main ideas.
} 
decumulation perception, we define the ratio of this EG-biased price to the unbiased price as $g(\theta) \equiv \frac{p_{\theta}}{p_{1}} \cdot{ }^{3}$

Negative EG bias leads to over-pessimism in understanding how large a stream of income can be supported by a given asset balance. Note that $\operatorname{sign}\left[g^{\prime}(\theta)\right]=\operatorname{sign}\left[\frac{d p_{\theta}}{d \theta}\right]=\operatorname{sign}\left[\frac{d}{d \theta} \frac{I_{\theta}}{B}\right]$ and that

$$
\begin{aligned}
\frac{d p_{\theta}}{d \theta} & =\frac{d}{d \theta} \frac{1}{\left(\frac{1}{R_{d}^{\theta}}+\frac{1}{R_{d}^{2 \theta}}+\ldots+\frac{1}{R_{d}^{T \theta}}\right)} \\
& =\frac{\ln R_{d}\left(\frac{1}{R_{d}^{\theta}}+\frac{2}{R_{d}^{2 \theta}}+\ldots+\frac{T}{R_{d}^{T \theta}}\right)}{\left(\frac{1}{R_{d}^{\theta}}+\frac{1}{R_{d}^{2 \theta}}+\ldots+\frac{1}{R_{d}^{T \theta}}\right)^{2}} \\
& >0 .
\end{aligned}
$$

Under negative EG bias $(\theta<1)$, the amount of income that is supported by a given balance at retirement is underestimated $\left(g(\theta)<1 \Rightarrow I_{\theta}<I_{1}\right)$.

Given this structure, the perceived contribution of saving to retirement income can be expressed as $f\left(A_{2} ; K, \theta\right)=g(\theta) R_{a}^{K \theta} A_{2}$, which can be substituted into the subjective budget constraint in equation (1). Increases in $\theta$ raise the perceived retirement income that can be generated from a given level of saving.

How should optimal saving respond to changes in EG bias $(\theta)$ ? The first-order condition for optimal saving is

$$
A_{2}^{*} \quad: \quad U^{\prime}\left(C_{1}^{*}\right)=g(\theta) p U^{\prime}\left(C_{2}^{*}\right)\left[\beta R_{a}^{\theta}\right]^{k} .
$$

An increase in the value of $\theta$ raises the perceived marginal benefit of saving in both accumulation and decumulation. This is qualitatively similar to an increase in expected rate of return $\left(R_{a}\right)$ in a standard saving model, although the factors enter the decision differently in the current model. Because these equations hold for each $\left(R_{a}, R_{d}, K, T\right)$, they are true

\footnotetext{
${ }^{3}$ Dependence on $R_{d}$ and $T$ is suppressed to keep notation simple.
} 
given uncertainty over these variables.

An increase in the subjective marginal benefit of saving has two countervailing effects: an income and a substitution effect. The substitution effect encourages people to reduce working period consumption and to save more because the marginal benefit of each dollar saved is higher. On the other hand, the increase in the subjective value of saving raises the subjective value of a person's endowment and encourages her to consume more in both periods, thereby reducing saving through the income effect. Therefore, the effect on optimal saving is ambiguous and depends on which effect dominates.

To understand how the optimal saving decision responds to changes in bias, we develop comparative statics. Let $\epsilon(\theta) \equiv-\frac{U^{\prime}\left(C_{2}^{*}\right)}{U^{\prime \prime}\left(C_{2}^{*}\right) g(\theta) p R^{k \theta} A_{2}^{*}}=-\frac{U^{\prime}\left(C_{2}^{*}\right)}{C_{2}^{*} U^{\prime \prime}\left(C_{2}^{*}\right)}$. In a model where there is no EG bias $(\theta=1)$, this expression is analogous to the standard elasticity of intertemporal substitution (EIS). As in the standard model, the EIS governs whether the increase in $\theta$ increases or decreases optimal saving.

Proposition 1. Given $U^{\prime \prime}<0, \beta>0$, and $R>1$,

$$
\operatorname{sign}\left[\frac{\partial A_{2}^{*}}{\partial \theta}\right]=\operatorname{sign}[\epsilon(\theta)-1]
$$

Proof in Appendix A.

The consensus in the literature is that $\theta<1$ (Wagenaar and Sagaria 1975; Eisenstein and Hoch 2007; Stango and Zinman 2009), which implies individuals have an overly-pessimistic view of the returns to saving, both in accumulation and decumulation. Assuming that our intervention reduces bias (i.e., increases $\theta$ towards 1 ), if we observe an increase (decrease) in saving on average, this suggests that EIS $>1($ EIS $<1) .{ }^{4}$ While unlikely, it is possible that our intervention increased bias by reducing $\theta$; an observed higher (lower) rate of saving would then imply that EIS $<1$ (EIS $>1$ ). Another possibility is that the intervention

\footnotetext{
${ }^{4}$ While the population is likely characterized by a distribution of values for $\epsilon(\theta)$, the implications for $\epsilon(\theta)$ and thus the EIS would be for the population mean.
} 
inadvertently shifts beliefs regarding one's retirement age or expected retirement return; we examine this possibility in Section 5.4.

\section{Experimental Design}

\subsection{Setting and Sample Characteristics}

The setting of our study is the University of Minnesota. Nearly all employees at the University participate in Social Security and a retirement plan that mandates relatively high levels of retirement saving. ${ }^{5}$ In addition to these mandatory plans, most employees are also eligible to participate in Voluntary Retirement Plans (VRPs), which allow them to make additional tax-deferred contributions of up to $\$ 33,000$ per year if they desire. Participants can choose to make a flat dollar amount election each pay period or contribute a percentage of their salary. ${ }^{6}$

For our experiment, we consider employees eligible to participate in the VRPs who were under age 65 at the time of our intervention. Our sample consists of 16,881 employees dispersed among 1,385 departments across 5 different campuses and extension offices who were employed by the University in both October 2010 (Period 1, prior to intervention) and May 2011 (Period 2, following the intervention). We obtain administrative data from the Office of Human Resources with the assistance of an independent third party in order to protect employee anonymity. We observe each employee's VRP contribution decision in

\footnotetext{
${ }^{5}$ Civil servants and non-faculty bargaining unit employees participate in the Minnesota State Retirement System (MSRS), while faculty, academic professionals, and administrators participate in the Faculty Retirement Plan (FRP). MSRS participants receive a defined benefit pension equal to 1.7 percent of the average of their five-highest salaries for each year of service starting at age 65 and reduced benefits for early retirement. Employees hired before July 1, 1989 are governed by a slightly different set of rules. The employee and employer each contribute 5 percent of the employee's gross salary to the retirement plan. FRP is a defined contribution plan in which eligible participants make a required tax-deferred contribution of 2.5 percent of their covered salary, matched by a 13 percent contribution by the University.

${ }^{6}$ There are two choices of VRP, the Optional Retirement Plan (ORP) and the Section 457 Plan. Participants must choose between several different vendors and investment options within each plan. Employees face a maximum annual tax-deferred contribution of $\$ 33,000$ (\$16,500 in each plan). Contributions automatically cease once a $\$ 16,500$ annual plan limit is reached. Individuals age 50 and above are allowed to make additional catch-up contributions of $\$ 5,500$ in the ORP plan annually.
} 
each period. ${ }^{7}$

Table 1 describes the administrative data for our study sample. In Period 1, 24.1 percent participate in a VRP while 24.9 percent participate in Period 2. Including contributions of zero for non-participants, the average contribution rate is 3.19 percent of salary prior to the intervention, equivalent to $\$ 2,324$ per year. In Period 2, the average contribution rate is 3.33 percent of salary, equivalent to $\$ 2,450$ per year.

Table 1 also includes a summary of the demographic characteristics of our sample. The majority of the sample is female (55.7 percent) and the average age is just under 45 years. Average employment tenure at the University is 12.3 years and average salary is nearly $\$ 60,000$. Employees eligible for the faculty retirement plan make up approximately 41 percent of the sample. The majority of the sample works at the Twin Cities campus, followed by the coordinate campuses of Duluth, Morris, Crookston, and Rochester. Approximately 6 percent of the sample works in off-campus locations. The age and gender composition of the sample is similar to a nationally-representative sample employed at firms with pension benefits, though more highly educated and more likely to be married and more likely to be white. We discuss the differences between our sample and a nationally-representative sample in greater detail in Appendix B.

\subsection{Treatment Groups and Intervention}

We randomly assign employees to four groups, a control group and three treatment groups, to examine the role of different aspects of the intervention. Table 2 provides a summary of the different informational interventions and treatment group sizes. The control group received no intervention. The most basic treatment, the planning treatment, provides general information on saving for retirement, steps to sign up for or change contributions to a VRP, and a chart describing VRP options. This planning treatment reduces transaction and

\footnotetext{
${ }^{7}$ We never observe VRP account balances or values of mandatory retirement accounts. This prevents us from offering total retirement income projections, as laid forth in the Lifetime Income Disclosure Act. We therefore focus our interventions on providing projections of additional retirement balance and income from hypothetical additional contributions while working, a marginal decision relevant for everyone.
} 
cognitive costs of saving but includes no projection component meant to affect understanding of exponential growth.

The other two treatments add components of the income disclosure meant to reduce individuals' EG bias. The balance treatment adds a customized projection of how hypothetical additional contributions would translate into additional assets at retirement. This is intended to improve individuals' understanding of the accumulation phase. To the balance treatment, the income treatment adds a customized projection of the additional annual retirement income that would be generated. By adding information regarding the decumulation phase, the income treatment aims to help people understand the full mapping from current contributions to retirement income. The balance treatment provides only partial information because it only shows the projected relationship between contributions and savings at retirement.

The treatment materials consist of a four-page color brochure sent through internal mail. The first page was designed to prompt individuals to think about their retirement goals (see Figure C-1 in Appendix C). The brochure was designed not to encourage people to save more or to save less, but to encourage them in a neutral manner to reflect on whether they are on target to achieve their retirement income goals. For individuals in the balance and income treatment groups, the second page contains the customized account balance projection (balance group) or both the balance and income projections (income group). The left-hand side of Figure C-2 shows an example second page for an employee in the income group. The top graphic contains the customized conversion of additional contributions to additional account balance at retirement, while the bottom graphic contains the customized conversion of additional contributions to additional annual income in retirement. This page is omitted for the planning treatment group. Enrollment requires choosing a VRP, deciding on a contribution election (i.e. either an amount or rate), selecting an investment company, and finally allocating the contribution to different investment options. This process is described step-by-step in an attempt to reduce the cognitive costs associated with enrollment in the 
third page of the brochure (Lusardi, Keller and Keller 2009), and is on the right-hand side of Figure C-2. This is page 2 for the planning treatment group. Figure C-3 reproduces the brochure's final page, a side-by-side comparison of the features of the two VRP options.

All groups that received a mailing also received a postcard to request a VRP enrollment kit from the Office of Human Resources. In addition, all individuals who participated in a VRP as of Period 1 were provided with a contribution change form to reduce the transaction costs involved with making a change in their election. Finally, individuals in the balance and income treatment groups were also provided with access to an online customization tool designed to mimic the information provided in the printed materials. Online tools of this type are readily available via investment companies' websites and would serve as complementary tools to any policy initiative surrounding income disclosure by plan sponsors. The online tool had the added ability to adjust assumptions regarding marital status, expected retirement age, and expected investment returns. Those in the income group could also add in other sources of retirement income and expected Social Security benefits to get a more comprehensive picture of their retirement savings portfolio. ${ }^{8}$ Figure C-4 provides an example screenshot of the online tool for a member of the income treatment group.

\subsection{Randomization}

We perform the randomization of our four treatment groups by department in order to mitigate possible contamination across groups, as the main intervention was delivered via department-based mail. We use matched-quad randomization (matched-pair randomization with four treatment groups) for the assignment to ensure that the groups are balanced on observable characteristics that may be related to changes in plan participation. To form the matched quads, we first block departments on quartiles of VRP participation rate, quartiles of average age, and quartiles of average salary. Within block, the largest 4 departments forms one quad, the fifth to eighth largest forms another quad, and so on, and treatment

\footnotetext{
${ }^{8}$ Projections on the printed materials were in nominal dollars. Individuals could input expected rate of inflation using the online tool.
} 
assignment is randomized within quad. This process ensures each treatment group contains a similar number of individuals and that only very small departments were in "quads" of less than 4 .

This process resulted in a total of 1,396 departments assigned to treatment groups from 374 quads. Department size ranges from 1 to 225. Because our analytic sample drops individuals no longer employed in Period 2, it includes slightly fewer departments in total. The number of departments and individuals in each treatment group is listed in that last two rows of Table 2. Unsurprisingly, the randomization procedure produced treatment groups balanced on observable characteristics. Further details are available in Appendix D.

\subsection{Projections and Assumptions}

We create customized projections of the additional account balance at retirement and the additional annual income in retirement that additional hypothetical contributions $c$ would generate. We observe each individual's current age $a$ and assume a retirement age $g$. We also assume a gross annual rate of return during accumulation, $R$. The projection of additional per-period contributions $c$ into additional account balance at retirement $b$ is performed as follows:

$$
b=\frac{c R^{(g-a-1+1 / 26)}}{R^{1 / 26-1}}
$$

Additional contributions $c$ are assumed to begin immediately and continue once per pay period, or every two weeks, for a total of 26 times per year until retirement at age $g$.

The translation of additional balance at retirement $b$ into additional income in retirement $y$ is simply:

$$
y=p_{g} b
$$

where $p_{g}$ represents the price of a joint annuity that pays $\$ 1$ each year from retirement at age $g$ until death for a married couple. The values $p_{g}$ were retrieved from the Income Solutions Annuity Calculator for married males and females of different ages. Married individuals are 
assumed to be the same age and receive joint life annuities that pay the survivor $100 \%$ of the benefit after the first member of the couple dies. ${ }^{9}$

Each individual in the balance treatment receives intervention materials with age-specific balance projections only, not income projections. Those in the income treatment receive both age-specific balance and income projections. In order to avoid creating a false sense of precision, projected balances were rounded to the nearest $\$ 1,000$ and annual retirement incomes to the nearest $\$ 100$.

The intent of this kind of disclosure intervention is to help people improve their understanding of the relationships in equations (5) and (6), not for the arbitrary values of $(c, g, R)$ used in the projections to influence behavior. However, assumptions are inherent in the policy of offering projections and a policy of providing projections could reduce welfare if these assumptions themselves affect saving behavior. This could happen in either of two ways. First, projection assumptions may inadvertently shift beliefs about the appropriate or likely values of these variables. Second, the assumptions may have framing effects in that individuals may respond differently to larger-valued projections relative to smaller-values, or be influenced by the hypothetical contribution amounts. To assess how using these assumptions in projections affects saving behavior and beliefs, we randomly assign alternative values of the 3 parameters among individuals in the balance and income treatment groups. Each person is randomized into one of 12 groups at the individual level, assigning one of three different rates of return, one of two different retirement ages, and one of two different sets of hypothetical additional contribution levels. The assumed net investment return is either 3,5 , or 7 percent and retirement age is either 65 or 67 . The set of hypothetical additional contribution values displayed on the horizontal axes of the projection graphs is either $\{\$ 0$, $\$ 50, \$ 100, \$ 250\}$ or $\{\$ 0, \$ 100, \$ 200, \$ 500\} . .^{10}$ By holding the relative magnitude of the contribution amounts in each set constant across the two versions (e.g., 50/100 $=100 / 200$ ), the

\footnotetext{
${ }^{9}$ The calculator is available at https://www.incomesolutions.com/AnnuityCalculator.aspx. The values used in this study were obtained September 14, 2010.

${ }^{10}$ For instance, the example in Figure C-2 uses $\{\$ 0, \$ 100, \$ 200, \$ 500\}$.
} 
graph itself remains fixed for everyone within treatment. Only the hypothetical contribution amounts printed under the axes, the projected balance or income amounts printed on top of the bars, and the text of the assumptions printed on the brochure vary between parameter treatments.

To obtain a single, comprehensive measure of the assumptions' impact on the projections that accounts smoothly for the fact that the impacts depend on an employee's age, we construct a ratio for each individual in the balance and income treatment groups of the realized projection printed on that individual's brochure and the corresponding value that would be shown if the assumptions that generate the lowest projection (3 percent return, retirement age of 65 , and the lower-valued contribution axes) had been used. This measure normalizes the different effects of the assumptions by age. For instance, for older employees, increasing the retirement age has a larger effect on projections than does increasing the investment return. For younger employees, investment return affects the projected values more. We label this ratio the "Relative projection magnitude" (RPM). The range of values for RPM is between 1 and 9 .

\subsection{Supplemental Follow-Up Survey}

We supplement administrative data with data collected from a web-based, follow-up survey. This data allows us to analyze heterogeneity in the effects of the treatment with respect to characteristics not available in the administrative records, such as time preferences, barriers to saving, and financial literacy. In addition, we investigate the effect of the interventions on the saving process to provide corroborative support for the treatment effect. Finally, the survey asks about beliefs regarding expected retirement income, expected rates of return, and expected retirement ages in order to assess the effects of the interventions on these beliefs. $^{11}$

\footnotetext{
${ }^{11}$ To the extent possible, we use validated survey questions from tested sources, such as Lusardi and Mitchell (2007); the National Financial Capability Study led by FINRA and designed by a multi-disciplinary team, including Annamaria Lusardi and Robert Willis; the Health and Retirement Study; and the General Social Survey as described in Oreopoulos and Salvanes (2011).
} 
In order to eliminate the possibility that the survey itself affected saving behavior, the survey was administered after the second administrative data pull. An independent, third party matched survey responses to administrative data and provided de-identified data for analysis. The overall response rate of the follow-up survey was approximately 22 percent. $^{12}$

While this response rate is similar to response rates found in many research studies, there is concern that survey responders may differ somewhat from the overall population of employees at the University of Minnesota. We find that while survey responders are more likely to be female, comprise a greater proportion of faculty, and are more likely to be VRP participants, the survey sample appears balanced on observable demographics across treatment groups. In addition, the observed treatment effects are substantially higher among the sample of follow-up survey responders. Additional details regarding the representativeness of the survey population are provided in Appendix D.

\section{Empirical Methods}

We examine both the propensity to make any change in one's saving behavior as well as the magnitude and direction of the change using two primary outcomes. Our first outcome is an indicator that the employee made any active change in his or her contribution between periods: $1(\Delta$ Contribution $)$. This includes changes in participation status as well as changes in contribution election among participants. Second, we measure the change between periods in the level of elected annual contributions, $\Delta$ Contribution Amount. ${ }^{13}$

Figure 1 depicts the means of the outcomes by group along with 95 percent confidence

\footnotetext{
${ }^{12}$ To encourage response, all individuals were sent a letter explaining the survey's purpose prior to being sent the email invitation with link. A $\$ 2$ monetary non-conditional incentive was provided to a random subsample at the outset of the experiment; however, no additional monetary incentive was provided for completing the survey. The incentive subsample's letter describing the survey also included a hand-written, "Thank you, [name]!" printed on their letter. This subsample had 9 percentage points greater response rate. All individuals who had not answered the survey after approximately two weeks were sent an email reminder.

${ }^{13}$ The majority of participants elect a dollar amount per pay period. A minority elect contributions as a share of pay, which induces a mechanical increase in contribution amount following a salary increase absent an active change. These two kinds of participants are randomly assigned across treatment groups. We exclude mechanical changes in 1 ( $\Delta$ Contribution) and $\Delta$ Contribution Amount. Including both active and mechanical changes or using saving rates relative to salary rather than amounts produce very similar results.
} 
intervals. The percentage of the sample that changes their contribution is 5.60 percent overall, but ranges from 4.09 in the control group to 5.30 in the income group. The average change in the contribution amounts is $+\$ 122.08$ per year and is highest among those sent the full income projections: $+\$ 157.29$. The change in amount increases with each additional layer of treatment. These descriptive measures provide suggestive evidence that each component of the income disclosure influences saving behavior.

We generate formal estimates of treatment effects on saving behavior in a regression framework. Given the experimental methodology, analysis is straightforward. We estimate the following equation:

$$
S_{i}=\alpha+T_{i} \delta+X_{i} \beta+\eta_{q}+\epsilon_{i, d}
$$

where $S_{i}$ is one of our two outcome measures, $T_{i}$ is a vector of treatment group dummy variables with control omitted, $X_{i}$ is a vector of demographic controls, and $\eta_{q}$ are randomizationquad fixed effects. The error term $\left(\epsilon_{i, d}\right)$ is clustered at the department-level $(d)$, the unit of primary randomization. The individual covariate vector $X_{i}$ contains quadratics in baseline individual age and tenure, log salary, percent change in salary between periods, and indicators for gender, faculty, and campus location. We also estimate the effect of the assumptions used in the projections by restricting the sample to individuals in the balance and income groups and estimating effects of the randomly-assigned projection assumptions on the same saving outcomes.

\section{Results}

\subsection{Effects on Saving Behaviors}

We first evaluate the effect of the interventions on the propensity to change one's contribution

election. Results are reported in the first three columns of Table 3. Column (1) reports treatment effects relative to the control group when using only the three treatment indicators. 
This simply tests for mean differences across groups. Column (2) adds randomization-quad fixed effects to control for observed and unobserved differences within quad. Column (3) adds individual covariates.

In column (1) the percentage of the planning group that changes their contribution election is not significantly different from that in the control group, though the balance and income group propensities are significantly higher. The estimated effects with additional covariates (columns (2) and (3)) are very similar in magnitude to column (1), though more precise and statistically significant. The results in column (3) indicate that the planning group is 0.8 percentage points more likely than the control group to change contributions, a marginally significant effect. The balance and income groups are 1.4 and 1.2 percentage points more likely to change respectively, with both effects statistically significant at the one percent level. Given the control group's propensity to change of 4.77 percent, these effects are economically meaningful. For instance, the income treatment raises the propensity to change one's election by 29 percent $\left(\frac{1.2}{4.09}=0.29\right)$ and the balance treatment by 34 percent.

In order to understand the magnitude and direction of the changes, we repeat the analysis using $\Delta$ Contribution Amount as the outcome. Results analogous to columns (1)-(3) are reported in columns (4)-(6) of Table 3. Only the income treatment produces a significantly different mean change in contributions, as reported in column (4). The results are robust to adding quad fixed effects and individual covariates in columns (5) and (6). Compared to the control group, individuals in the income treatment increased their saving by an additional $\$ 85.42$ annually. The standard deviation of $\Delta$ Contribution Amount in the control group is $\$ 1,849$; therefore, our intervention produced a 0.046 effect size.

The increase is economically meaningful. Compared to the control group mean change of $+\$ 83.40$, the income treatment more than doubled the average change. Further, the average changes contain zeros for the vast majority of employees who made no changes. Among employees who made an active change, those in the income treatment group increased saving by $\$ 1,152$ more per year than did control-group changers. When examining initial participants 
and initial non-participants separately, the point estimates suggest that this effect is driven by changes among initial participants rather than differences in the amount contributed between new participants in each treatment group (results available upon request).

To better understand what features of the full intervention contribute to this increase in contributions, we can compare the treatment effects among the income group to those in the planning and balance groups using the estimates from Table 3. Relative to the control group, neither the planning nor balance treatment displayed a statistically significant increase in contributions. Each part of the income treatment (i.e. planning materials and balance and income projections) seemed to contribute positively to the positive treatment effect on saving changes as the point estimates increase with each additional layer of treatment. There is not strong evidence that any layer nor any two layers alone induced a significant increase in contributions. These findings suggest that the mailing induced a response in part by reducing the transaction costs associated with changing participation status and contribution levels (planning treatment). Furthermore, they suggest that the relationship between current contributions and income in retirement was not completely understood prior to the intervention, as the information contained in the income treatment led individuals to change their rate of saving on average.

We can interpret the findings in the context of our model in Section 2 under certain assumptions. First, we assume, based on evidence from the literature, that individuals suffer negative EG bias on average. This assumption implies that the average $\theta$ in the control and planning groups is less than $1\left(\theta^{C}=\theta^{P}<1\right)$. Second, because the projections we sent provided accurate information by construction and because the income treatment provided more information than the balance treatment, we assume that the treatments did not increase bias $\left(\theta^{C} \leq \theta^{B} \leq \theta^{I} \leq 1\right)$. Under Proposition 1 , given that we observe an increase in saving as a result of our intervention, our findings suggest EIS $>1$ in the sample.

Past studies have used a variety of macroeconomic and microeconomic techniques and contexts to estimate the EIS. Many estimates to date have ranged between zero and one, 
with the most recent estimates being closer to one (e.g., Attanasio and Weber 1993; VissingJorgensen 2002; Guvenen 2006; Scholz, Seshadri and Khitatrakun 2006; Engelhardt and Kumar 2009). ${ }^{14,15}$ Interestingly, in the realm of retirement savings, studies have found that individual contributions respond positively to employer match rates in 401(k) plans (e.g., Choi, Laibson and Madrian 2006; Engelhardt and Kumar 2007) and IRA contributions increase with the Saver's Credit (Duflo, Gale, Liebman, Orszag and Saez 2006), suggesting that the EIS may in fact be greater than one. Engelhardt and Kumar (2009) use variation in employer match rates for individuals in the Health and Retirement Study and estimate the EIS to be 0.74 , with a confidence interval that includes values greater than one. In other words, our results are consistent with other studies in the retirement saving literature that saving rates increase with the return to saving, but differ in that we use an experimental design to identify whether the EIS is larger or smaller than one.

\subsection{Effects on the Saving Process}

Changes in saving behavior must occur through a multi-step process. We test whether the interventions affected engagement in steps and attitudes that are likely part of this process using data from our follow-up survey described in Section 3.5.

The survey provided respondents with the following statements:

- "It is difficult to find information that will help me decide how much to save for retirement."

- "I am better informed about retirement planning than I was 6 months ago."

- "In the last 6 months, have you tried to figure out how much you need to save for retirement?"

- "I understand how savings today could affect my retirement income."

- "How certain are you about the amount of annual retirement income you expect your household to have?"

\footnotetext{
${ }^{14}$ One exception is Gruber (2006) which estimates an EIS $\approx 2$ using variation in the capital income tax rate across individuals.

${ }^{15}$ Vissing-Jorgensen (2002) and Guvenen (2006) note heterogeneity in the EIS across households based on asset holdings and evidence that households with higher assets have larger values of the EIS.
} 
- "Overall, thinking of your assets, debts and savings, how satisfied are you with your current personal financial condition?"

Respondents were asked to rate their agreement, level of certainty, or satisfaction level on a 7-point scale with the exception of the third question which required a simple Yes/No response. ${ }^{16,17}$ To conduct our analysis, we construct Z-scores of the scaled responses for each item by subtracting the sample mean and dividing by the sample standard deviation.

Table 4 displays the results of estimating Equation 7 on the outcome measures described above, including quad fixed effects and the same individual covariates. The dependent variables in Columns 1, 2, 4, 5 and 6 are specified as Z-scores; therefore, the interpretation of a coefficient $\delta$ on a particular treatment group dummy indicates that that treatment increased the outcome measure by $\delta$ standard deviations relative to the control group. The dependent variable in Column 3 is a simple binary measure with Yes coded as 1.

The income treatment had a statistically significant impact on almost all measured aspects of the retirement saving process. Specifically, the point estimates indicate that, relative to the control group, the income group's difficulty in finding information to decide how much to save for retirement is 0.12 standard deviations lower; they are 0.20 standard deviations higher in their informedness about retirement planning relative to 6 months prior; they are 5.1 percentage points (or 12 percent) more likely to have figured out how much to save for retirement; they are 0.10 standard deviations more certain about their retirement income; and 0.078 standard deviations higher in their financial satisfaction. None of the treatment groups differed significantly in their reported understanding of how savings today can affect income in retirement. However, responses to this question are heavily concentrated in the "strongly agree" bin (see Figure E-1 in Appendix E for detail).

These results are interesting for a number of reasons. First, they provide evidence that the income disclosures have important implications for various steps in the retirement planning

\footnotetext{
${ }^{16}$ The distributions of responses to all survey items are provided in Figures E-1 to E-4 in Appendix E.

${ }^{17}$ All survey questions offered respondents the ability to answer "Don't know" and "Prefer not to say" in order to maintain comparability with the validated survey questions and improve the quality of the provided responses. These responses were coded as missing in this and subsequent analysis.
} 
process. There are significant effects on steps that would conceivably occur prior to making changes in retirement contributions (finding information, being informed about retirement planning, and figuring how much to save for retirement) as well as outcomes that may be more apparent later in the process (being more certain about their expected retirement income and more satisfied with their financial condition). Second, these results show that individuals in the planning and balance groups, who were sent either no income projections or incomplete income projections, generally do not have statistically different outcomes relative to the control group, suggesting that full income projections drive the observed effects. Finally, the results suggest that the treatment effects on saving behaviors are not spurious or driven by a small group of outliers and are the result of more informed saving decisions.

\subsection{Heterogeneity of Effects on Saving Behaviors}

We investigate the presence of heterogeneity in the effect of our interventions by measuring characteristics believed to influence saving decisions. In particular, we investigate the degree to which treatment effects interact with factors that would matter in a standard rationalactor model (time preference and liquidity constraints), measures of time-inconsistent preferences (self-control and procrastination), and measures of limited cognition (comfort using retirement planning aides and financial literacy). For each measure, we convert individuals' survey responses into Z-scores and then investigate the impact of interactions between the Z-score and treatment indicators on $\Delta$ Contribution Amount. The interpretation of the coefficients of these interactions is the change in the treatment effect for someone with a one standard deviation higher Z-score on the measure.

\subsubsection{Standard factors: time preference and liquidity}

Importantly, it may be optimal for some individuals not to respond to the intervention. In particular, even if the intervention increased understanding of exponential growth, individuals with high time discounting or high liquidity constraints may not find it optimal to save 
more, especially in our context which is characterized by high rates of mandatory saving. In fact, a potential benefit of a financial literacy intervention as opposed to forced saving is that it allows for heterogeneous response to the information, which we can investigate using the rich data from our survey.

Our measure of time preference comes from respondents rating how much they agree or disagree with the following statement on a 7-point scale: "Nowadays, a person has to live pretty much for today and let tomorrow take care of itself." 18 The average sample respondent agrees with this statement. To measure liquidity constraints the survey asks, "In a typical month, how difficult is it for you to cover your expenses and pay all your bills?" with options, "Not at all," "Somewhat," and "Very." The average respondent is not liquidity constrained.

The first two columns of Table 5 display the results of estimating Equation 7 on the change in contribution amount among our survey subsample, including the Z-score of the response to the statement indicated in the column heading along with the Z-score interacted with our treatment dummies, and our standard set of control variables. Here, we are interested in whether the effects of our interventions vary across different survey responses, conditional on completing the survey.

There is evidence of heterogeneity in the treatment effects with respect to both factors predicted by the standard model. Specifically, a one standard deviation increase in our measure of time discounting is associated with a $\$ 208$ reduction in the change in contribution amount for the income group, suggesting that individuals with higher discount rates are less likely to respond to the income treatment. Liquidity constraints also seem to matter as theory would predict. Those who report being more constrained increase their saving less in response to both the balance and income treatments. Specifically, a standard deviation increase in one's response to the difficulty in covering expenses reduces the income treatment effect by $\$ 181$ and the balance treatment effect by $\$ 198$. Therefore, these findings confirm that this intervention had at least some scope for individuals to react rationally to the

\footnotetext{
${ }^{18}$ The General Social Survey has long used this item and Oreopoulos and Salvanes (2011) discuss its value as a measure of time preference.
} 
information.

\subsubsection{Time-inconsistency}

As opposed to rational economic factors, the role of behavioral influences, such as timeinconsistency and tendencies to procrastinate, on retirement saving is now well-known. To measure these factors, the survey asks how strongly respondents agree or disagree with the following statements:

- "When I make a plan to do something, I am good at following through."

- "I tend to put off thinking about how much money I need to save for retirement."

As reported in column (3), a one standard deviation increase in one's self-reported ability to follow through with plans is associated with a $\$ 320$ increase in the income treatment's effect on changes in saving. As reported in column (4), a one standard deviation increase in putting off thinking about saving for retirement leads to a $\$ 233$ decrease in the effect of the income treatment.

These results point to an interaction between informational and behavioral factors, which are often treated as separate, alternative explanations for lack of saving. In particular, the findings suggest that policies that seek to inform individuals about the return to saving will be most effective among those without tendencies to procrastinate.

\subsubsection{Limited Cognition}

Cognitive barriers are the other set of factors hypothesized to influence retirement saving

decisions. We can evaluate how our treatment, which is designed to target one aspect of limited cognition (i.e. understanding of exponential growth) interacts with other cognitive limitations. To do this, we provide two statements regarding cognitive barriers and ask for respondents' agreement on a 7-point scale:

- "I find most retirement planning information easy to use." 
- "I find it overwhelming to think about how much I need to save for retirement."

We also measure financial literacy. We present results using a composite financial literacy measure that combines both self-assessed and objective measures based on responses to a standard set of financial literacy questions. ${ }^{19}$

As the last three columns of Table 5 show, we find no evidence that cognitive barriers to saving mediate the estimated treatment effects. We also examine whether there are nonlinear interactions between cognitive limitations and our interventions, as theory may predict that those with low cognitive ability would be overwhelmed by the treatment and those with high cognitive ability would already know the content of the interventions. However, we find no evidence of these non-linear interactions. These results suggest that the intervention was equally effective on individuals who are more and less cognitively capable. One possibility for this finding is that our sample is more educated and more financially savvy (as well as more homogenous in these two dimensions) as compared to most Americans (see Tables B-1 and B-2).

We also explored interactions with available demographic and administrative variables, such as age and income but did not find evidence of statistically significant interactions. These findings imply that while these characteristics may influence one's level of saving, they do not affect the response to the treatment in terms of changes in saving amounts.

\footnotetext{
${ }^{19}$ The first measure of self-assessed financial literacy comes from the answer to, "On a scale from 1 to 7 , where 1 means very low and 7 means very high, how would you assess your overall financial knowledge?" The second measure is a composite of the following statements:

- "I regularly keep up with economic and financial news."

- "I am pretty good at math."

- "I am good at dealing with day-to-day financial matters, such as checking accounts, credit and debit cards, and tracking expenses."

The questions which test actual financial literacy are provided in Appendix F. The distribution of responses is provided in Figure E-3. Survey respondents tend to score themselves highly on self-assessed financial literacy measures and answer, on average, approximately four out of six financial literacy questions correctly. We construct Z-scores for each of the four self-assessed financial literacy questions and for the number of questions correctly answered on the financial literacy quiz. The composite measure is simply the sum of the Z-scores across these components. Analysis based on any of these dimensions of financial literacy alone yields similar results.
} 


\subsection{Effects of Projection Assumptions on Outcomes}

As discussed earlier, an important part of any policy aimed at requiring the disclosure of retirement income projections is the decision about what assumptions to use in the calculation. Assumptions regarding the rate of investment return and retirement age affect the magnitude of the projected values and could affect one's response to the information or beliefs about those future values. In addition, any hypothetical contribution amounts used to illustrate the projections may affect the behavior of individuals due to framing effects. Restricting the sample to individuals in either of these two treatment groups, we study the effect of the different projection assumptions — rate of investment return, retirement age, and hypothetical additional contribution amounts - on our two measures of saving behaviors.

The results in columns (1), (2), and (3) in Table 6 show the effect of each assumption separately on the propensity to make a contribution change, 1 ( $\Delta$ Contribution). Column (4) includes the natural log of the relative projection magnitude, described earlier. The coefficient on $\ln (\mathrm{RPM})$ is the estimated effect of a one-unit increase - corresponding to an approximate doubling of the balance and income projections - has on one's propensity to make a change. Column (5) shows the results of including all of the assumptions and the $\ln (\mathrm{RPM})$ simultaneously.

The results suggest only the retirement age assumption had a significant effect on the propensity to make any change. In column (4), we see that the relative magnitude projection, as captured by the $\ln (\mathrm{RPM})$, has no significant direct effect. In column (5), when all factors are included, the effect of the higher retirement age persists, suggesting the retirement age assumption affects the response through a channel other than the size of the projection.

Table 7 repeats the specifications described above with the continuous outcome measure, $\Delta$ Contribution Amount. The results suggest that a higher assumed retirement age and higher-valued axes both lead to larger positive changes in saving, as does the relative projection magnitude. For instance, presenting individuals with the higher-valued axes instead of the lower-valued axes increased annual contributions by $\$ 104$ on average, or by an additional 
$\$ 1,233$ per year among changers. However, we find no evidence that the assumed rate of investment return affects saving behaviors. In addition, the effect of the relative projection magnitude disappears after retirement age is controlled for.

Theoretically, the fact that assuming a later retirement age leads to increased retirement saving is difficult to reconcile with an economic model of shifting beliefs. If the higher retirement age assumption shifted beliefs towards a later retirement age, standard consumptionsmoothing models would predict reduced saving as later retirement would lead to more labor income available to save and fewer years of decumulation during retirement to finance. However, we find the opposite effect, which is consistent with larger projections producing higher levels of saving, rather than operating through beliefs.

We use the survey to further substantiate this conclusion. In particular, the survey asks respondents to report the age at which they expect to claim retirement benefits as well as the average annual real rate of investment return they expect to earn until retirement. ${ }^{20}$ First, we find that the average expected retirement age among the control and planning groups (who were not sent any projections) were 65.63 and 66.01 (see Figure E-4 in Appendix E), very close to our average retirement age assumption of 66 . Similarly, the average expected investment return among the control and planning groups is 5.29 and 5.42, only slightly higher than our average investment return assumption of 5 percent. The value of these beliefs, which were independent of our intervention, suggest that our assumptions are not likely to have shifted mean beliefs about these values among individuals sent the projections.

Second, we regress beliefs regarding expected retirement age and expected rates of return on treatment dummies. We then restrict attention to the balance and income treatment groups and investigate whether the brochure assumptions, which were randomly assigned, influence the mean expected retirement age and expected rate of return reported. Table 8 shows the results. We find no evidence that either the interventions or the assumptions used for the balance and income groups had a systematic effect on beliefs about these assump-

\footnotetext{
${ }^{20}$ We winsorize the top and bottom 1 percent of the expected retirement age distribution and the top 5 percent of the expected return distribution to guard against sensitivity to outliers.
} 
tions. $^{21}$

These results suggests that employee response is sensitive to psychological framing effects that operate through the magnitude of the projection, consistent with prior work (e.g., Bernheim and Rangel 2009; Bernheim et al. 2011; Choi, Haisley, Kurkoski and Massey 2012). While we interpret our results as framing effects in that we do not see evidence that the contribution amounts were focal (i.e. no increased prevalence of elections at exactly $\$ 200$ or $\$ 500$ among those assigned the high-valued axis nor at $\$ 50$ among those assigned the low-valued axis, nor changes of those amounts), they are also consistent with the most basic definition of anchoring in which respondents tend toward the arbitrary anchor value (Tversky and Kahneman 1974). These findings illustrate that care must be taken in the design of disclosures to avoid unintended consequences as they have the capacity to nudge individuals' decisions.

\section{Conclusion}

The shift toward DC retirement plans has placed much of the responsibility and risk for retirement security in the hands of individuals rather than institutions. Optimal retirement saving behavior in this current landscape requires an understanding of the relationship between current contributions and income in retirement, but requires a level of financial sophistication that many Americans may lack. The fact that individuals sent income projections changed their contributions relative to a control group suggests that this relationship is not universally well-understood. Based on the evidence in the literature on exponential growth bias and the theoretical model we develop, our empirical findings suggest that, on average, the elasticity of intertemporal substitution is greater than one, i.e. individuals save

\footnotetext{
${ }^{21} \mathrm{We}$ also investigate the impact of the interventions and assumptions on certainty about retirement age and future investment returns. We find the income treatment had a positive, statistically significant effect on certainty about these assumptions, suggesting the treatment reduced the variance of beliefs. This result could be welfare-enhancing if it occurred via the induced planning behavior and learning. However, it could also reflect an unintended, welfare-reducing effect of the interventions if it reflects a collapsing of subjects' prior beliefs towards assumed levels used in the projections.
} 
more in response to a higher perceived return to saving.

The results of our follow-up survey provide corroborative evidence that the intervention influenced saving decisions. On the one hand, we find that higher discount rates and liquidity constraints mitigate the effects of our interventions, which is consistent with known tradeoffs in saving decisions and supports the under-appreciated fact that not responding to an intervention may be optimal. On the other hand, we find that the effect of the intervention was dampened by procrastination tendencies suggesting that policies designed to increase financial literacy will interact with other behavioral considerations. Furthermore, those sent full income projections report less difficulty finding information regarding retirement planning, are better informed about retirement planning, and are more likely to have figured out how much to save. They are also more certain about their expected retirement income, and rate themselves higher in overall financial satisfaction.

This study provides proof of concept for a policy that requires no additional mandate on individuals or subsidy for saving. Providing retirement income projections - an extremely low-cost intervention - can actually affect individuals' saving behavior. The effects manifested were not large on average and were found in only in a small share of the sample; thus, this policy is not likely to lead to a saving revolution. However, among those who made changes, effects were substantial and suggest that similar policies may help some individuals move closer to their retirement goals.

The findings from the study also pose a policy challenge by demonstrating the sensitivity of saving behavior to projection assumptions. The concern is that individuals may be susceptible to any overly-optimistic assumptions and induced to oversave, or, analogously, to undersave from overly-pessimistic projections. Supplementing simple projections with accessible tools that give people a richer chance to explore how outcomes depend on saving choices under a wide range of assumptions and uncertainty may counteract the effect of framing.

The study offers the first direct evidence of the potential value of the kind of intervention 
recently proposed by Congress. The policy intervention is still under debate and the findings from this study may be informative. However, the intervention tested here differs in some dimensions from the current congressional proposal. First, the intervention was a one-time mailing sent via an employee's work mail, while the proposed initiative would likely include information in a quarterly statement sent to one's home. Second, while the proposed policy would only require projections be sent to those with active DC accounts, this intervention was also sent to individuals not currently contributing. Third, we did not have access to current account balances and therefore could not provide total projected retirement income. Fourth, the sample of employees at the University of Minnesota is more highly educated, more financially literate, and engaged in higher levels of mandatory retirement saving than Americans generally. While there is room for debate, there are reasons to think each of these factors would lead these study results to understate the true effects of the policy in the national population. 


\section{References}

Ameriks, John, Andrew Caplin, John Leahy, and Tom Tyler, "Measuring SelfControl Problems," American Economic Review, 2007, 97 (3), 966-972.

Attanasio, Orazio P. and Guglielmo Weber, "Consumption Growth, the Interest Rate, and Aggregation," Review of Economic Studies, 1993, 60 (3), 631-49.

and _ _ "Consumption and Saving: Models of Intertemporal Allocation and Their Implications for Public Policy," Journal of Economic Literature, 2010, 48 (3), 693-751.

Bernheim, B. Douglas and Antonio Rangel, "Beyong Revealed Preference: ChoiceTheoretic Foundations for Behavioral Welfare Economics," Quarterly Journal of Economics, 2009, 124 (1), 51-104.

, Andrey Fradkin, and Igor Popov, "The Welfare Economics of Default Options: A Theoretical and Empirical Analysis of 401(k) Plans," NBER Working Paper 17587, National Bureau of Economic Research 2011.

Beshears, John, James J. Choi, David Laibson, and Brigitte C. Madrian, "The Importance of Default Options for Retirement Savings Outcomes: Evidence from the United States," NBER Working Paper No. 12009, National Bureau of Economic Research 2006.

Buessing, Marric and Mauricio Soto, "Getting to the Top of Mind: How Reminders Increase Saving," Technical Report, Cetner for Retirement Research at Boston College February 2006.

Card, David, Stefano DellaVinga, and Ulrike Malmendier, "The Role of Theory in Field Experiments," Journal of Economic Perspectives, 2011, 25 (3), 39-62.

Charness, G. and P. Kuhn, "Lab Labor: What Can Labor Economists Learn from the Lab?," Handbook of Labor Economics, 2011, 4, 229-330.

Choi, James J., David Laibson, and Brigitte C. Madrian, "Reducing the Complexity Costs of 401(k) Participation Through Quick Enrollment," NBER Working Paper 11979, National Bureau of Economic Research 2006.

, and Andrew Metrick, "For Better or For Worse: Default Effect and 401(k) Savings Behavior," in David A. Wise, ed., Perspectives in the Economics of Aging, Chicago, IL: University of Chicago Press, 2004.

, Emily Haisley, Jennifer Kurkoski, and Cade Massey, "Small Cues Change Savings Choices," NBER Working Paper 17843, National Bureau of Economic Research 2012.

De Nardi, Mariacristina, Eric French, and John B. Jones, "Why Do the Elderly Save? The Role of Medical Expenses," Journal of Political Economy, 2010, 118 (1), 39-75. 
Duflo, Ester, William Gale, Jeffrey Liebman, Peter Orszag, and Emmanuel Saez, "Saving Incentives for Low- and Middle-Income Families: Evidence from a Field Experiment with H\&R Block," Quarterly Journal of Economics, 2006, 121 (4), 1311-1346.

Duflo, Esther and Emmanuel Saez, "The Role of Information and Social Interactions in Retirement Plan Decisions: Evidence from a Randomized Experiment," Quarterly Journal of Economics, 2003, 118 (3), 815-842.

Eisenstein, Eric M. and Stephen J. Hoch, "Intuitive Compounding: Framing, Temporal Perspective, and Expertise," Working Paper, Cornell University 2007.

Engelhardt, Gary V. and Anil Kumar, "Employer Matching and 401(k) Saving: Evidence from the Health and Retirement Survey," Journal of Public Economics, 2007, 91, $1920-1943$.

_ _ and _ _ "The Elasticity of Intertemporal Substitution: New Evidence from 401(k) Participation," Economics Letters, 2009, 103, 15-17.

Even, William and David Macpherson, "Defined Contribution Plans and the Distribution of Pension Wealth," Industrial Relations, 2007, 46 (3), 551-581.

Goda, Gopi Shah and Colleen Flaherty Manchester, "Incorporating Employee Heterogeneity into Default Options for Retirement Plan Selection," NBER Working Paper 16099, National Bureau of Economic Research 2010.

Gruber, Jonathan, "A Tax-Based Estimate of the Elasticity of Intertemporal Substitution," NBER Working Paper 11945, National Bureau of Economic Research 2006.

Guvenen, Fatih, "Reconciling Conflicting Evidence of the Elasticity of Intertemporal Substitution: A Macroeconomic Perspective," Journal of Monetary Economics, 2006, 53, $1452-1472$.

Hacker, Jacob S., The Great Risk Shift, Oxford University Press, 2006.

List, J.A., "Why Economists Should Conduct Field Experiments and 14 Tips for Pulling One Off," The Journal of Economic Perspectives, 2011, 25 (3), 3-15.

Lusardi, Annamaria and Olivia Mitchell, "Financial Literacy and Retirement Preparedness: Evidence and Implications for Financial Education," Business Economics, 2007, 42 (1), 35-44.

and Olivia S. Mitchell, "Financial Literacy and Planning: Implications for Retirement Wellbeing," NBER Working Paper 17078, National Bureau of Economic Research 2011.

, Punam Anand Keller, and Adam M. Keller, "New Ways to Make People Save: A Social Marketing Approach," NBER Working Paper 14715, National Bureau of Economic Research 2009. 
Madrian, Brigitte C. and Dennis F. Shea, "The Power of Suggestion: Inertia in 401(k) Participation and Savings Behavior," Quarterly Journal of Economics, 2001, 116 (4), $1149-1525$.

Mitchell, Olivia S., Gary R. Mottola, Stephen P. Utkus, and Takeshi Yamaguchi, "Default, Framing, and Spillover Effects: The Case of Lifecycle Funds in 401(K) Plans," NBER Working Paper 15108, National Bureau of Economic Research 2009.

Oreopoulos, Philip and Kjell G. Salvanes, "Priceless: The Nonpecuniary Benefits of Schooling," Journal of Economic Perspectives, 2011, 25 (1), 159-184.

Scholz, John Karl, Ananth Seshadri, and Surachai Khitatrakun, "Are Americans Saving 'Optimally' for Retirement?, Journal of Political Economy, 2006, 114 (4), 607643.

Skinner, Jonathan, "Are You Sure You're Saving Enough for Retirement?," Journal of Economic Perspectives, 2007, 21 (3), 59-80.

Song, Changcheng, "Financial Illiteracy and Pension Contributions: A Field Experiment on Compound Interest in China," mimeo., University of California, Berkeley 2012.

Stango, Victor and Jonathan Zinman, "Exponential Growth Bias and Household Finance," Journal of Finance, 2009, 64 (6), 2807-2849.

Thaler, Richard and Shlomo Benartzi, "Save More Tomorrow: Using Behavioral Economics to Increase Employee Saving," Journal of Political Economy, 2004, 112 (1), S164-S187.

Tversky, Amos and Daniel Kahneman, "Judgement under Uncertainty: Heuristics and Biases," Science, 1974, 185, 1124-1131.

Vissing-Jorgensen, Annette, "Limited Asset Market Participation and the Elasticity of Intertemporal Substitution," Journal of Political Economy, 2002, 110, 825-253.

Wagenaar, William M. and Sabato D. Sagaria, "Misperception of Exponential Growth," Perception \& Psychology, 1975, 18 (6), 416-422. 
Table 1: Summary Statistics: Administrative Data

\begin{tabular}{lcccc}
\hline \hline & mean & sd & $\min$ & $\max$ \\
\hline 1(VRP Participant, pre) & 0.241 & 0.428 & 0 & 1 \\
1(VRP Participant, post) & 0.249 & 0.432 & 0 & 1 \\
VRP Contr. Rate, pre & 3.189 & 8.933 & 0 & 100 \\
VRP Contr. Rate, post & 3.334 & 9.157 & 0 & 100 \\
VRP Contr. Amount, pre & 2323.9 & 6407.7 & 0 & 38500 \\
VRP Contr. Amount, post & 2450.1 & 6589.2 & 0 & 38500 \\
1(Female) & 0.557 & 0.497 & 0 & 1 \\
Age & 44.89 & 11.16 & 19 & 64 \\
Tenure & 12.34 & 9.387 & 0.301 & 46.64 \\
Salary, pre & 58386.9 & 32527.5 & 480.7 & 686587.5 \\
Salary, post & 59227.1 & 33348.7 & 480.7 & 686587.4 \\
1(Faculty Ret. Plan) & 0.412 & 0.492 & 0 & 1 \\
1(Twin Cities campus) & 0.810 & 0.393 & 0 & 1 \\
1(Crookston campus) & 0.0129 & 0.113 & 0 & 1 \\
1(Duluth campus) & 0.0890 & 0.285 & 0 & 1 \\
1(Morris campus) & 0.0206 & 0.142 & 0 & 1 \\
1(Rochester campus) & 0.00427 & 0.0652 & 0 & 1 \\
1(Off-campus) & 0.0636 & 0.244 & 0 & 1 \\
\hline Observations & 16881 & & & \\
\hline \hline
\end{tabular}


Table 2: Treatment Group Summary

\begin{tabular}{l|cccc}
\hline \hline & Control & Planning & Balance & Income \\
\hline $\begin{array}{l}\text { General information on saving for re- } \\
\text { tirement and signing up for VRP }\end{array}$ & & $\checkmark$ & $\checkmark$ & $\checkmark$ \\
\hline $\begin{array}{l}\text { Customized information regarding con- } \\
\text { version of hypothetical additional con- } \\
\text { tributions to additional account bal- }\end{array}$ & & & $\checkmark$ & $\checkmark$ \\
ance at retirement & & & & \\
\hline $\begin{array}{l}\text { Customized information regarding con- } \\
\text { version of hypothetical additional con- } \\
\text { tributions to additional annual in- } \\
\text { come in retirement }\end{array}$ & & & & $\checkmark$ \\
\hline $\begin{array}{l}\text { Number of departments } \\
\text { Number of individuals }\end{array}$ & 344 & & & \\
\hline \hline
\end{tabular}

Notes: VRP stands for Voluntary Retirement Plan and is a tax-deferred savings plan to which employees in the sample can contribute. 
Table 3: Effect of Interventions

\begin{tabular}{lcccccc}
\hline \hline Outcome: & \multicolumn{3}{c}{$1(\Delta$ Contrib. } & \multicolumn{3}{c}{$\Delta$ Contrib. Amt. } \\
& $(1)$ & $(2)$ & $(3)$ & $(4)$ & $(5)$ & $(6)$ \\
\hline 1(Planning) & 0.007 & $0.009^{* *}$ & $0.008^{*}$ & 23.926 & 35.979 & 36.322 \\
& $(0.005)$ & $(0.004)$ & $(0.004)$ & $(43.326)$ & $(37.695)$ & $(38.473)$ \\
1 (Balance) & $0.012^{* *}$ & $0.014^{* * *}$ & $0.014^{* * *}$ & 56.074 & 57.482 & 59.703 \\
& $(0.005)$ & $(0.004)$ & $(0.004)$ & $(44.032)$ & $(40.768)$ & $(40.850)$ \\
& $0.012^{* *}$ & $0.013^{* * *}$ & $0.012^{* * *}$ & $73.890^{*}$ & $89.363^{* *}$ & $85.424^{* *}$ \\
& $(0.005)$ & $(0.004)$ & $(0.004)$ & $(43.465)$ & $(36.988)$ & $(37.017)$ \\
& & & & & & \\
Quad FEs & No & Yes & Yes & No & Yes & Yes \\
Controls & No & No & Yes & No & No & Yes \\
Adj. R ${ }^{2}$ & 0.000 & 0.013 & 0.022 & 0.000 & -0.002 & 0.000 \\
& & & & & & \\
Control Mean & 0.0409 & 0.0409 & 0.0409 & 83.4000 & 83.4000 & 83.4000 \\
& & & & & & \\
Departments & 1,385 & 1,385 & 1,385 & 1,385 & 1,385 & 1,385 \\
Individuals & 16,881 & 16,881 & 16,881 & 16,881 & 16,881 & 16,881 \\
\hline \hline
\end{tabular}

Notes: $\mathbf{1}(\Delta$ Contrib. $)$ is an indicator for whether there was any change in the election and $\Delta$ Contrib. Amt. is Period 2 annual contribution dollar amount minus Period 1 annual contribution dollar amount. Control group is the excluded category. Sample is restricted to employees present in both Period 1 and Period 2. Standard errors clustered at unit of randomization (Department) with unit of stratification fixed effects. Control variables in columns (3) and (6) include a gender indicator variable, quadratic in age, quadratic in tenure, $\ln$ (salary), percentage change in salary, faculty indicator, and indicators for different campuses. * Significantly different at the $10 \%$ level; ** at the $5 \%$ level; $* * *$ at the $1 \%$ level. 
Table 4: Effects of Interventions on Additional Aspects of Saving Process

\begin{tabular}{ccccccc}
\hline \hline & $(1)$ & $(2)$ & $(3)$ & $(4)$ & $(5)$ & $(6)$ \\
\hline & $\begin{array}{c}\text { Diff. to } \\
\text { find info }\end{array}$ & $\begin{array}{c}\text { Better } \\
\text { informed }\end{array}$ & $\begin{array}{c}\text { Figured ret. } \\
\text { savings }\end{array}$ & $\begin{array}{c}\text { Understand } \\
\text { sav-inc }\end{array}$ & $\begin{array}{c}\text { Ret. income } \\
\text { certainty }\end{array}$ & $\begin{array}{c}\text { Financial } \\
\text { satisfaction }\end{array}$ \\
1 (Planning) & -0.061 & 0.067 & 0.022 & -0.002 & -0.000 & -0.001 \\
& $(0.044)$ & $(0.042)$ & $(0.021)$ & $(0.046)$ & $(0.040)$ & $(0.040)$ \\
1 (Balance) & -0.052 & $0.084^{* *}$ & 0.018 & -0.019 & 0.009 & -0.021 \\
& $(0.048)$ & $(0.041)$ & $(0.023)$ & $(0.046)$ & $(0.042)$ & $(0.039)$ \\
1 (Income) & $-0.123^{* *}$ & $0.201^{* * *}$ & $0.051^{* *}$ & 0.060 & $0.102^{* *}$ & $0.078^{*}$ \\
& $(0.048)$ & $(0.045)$ & $(0.021)$ & $(0.052)$ & $(0.040)$ & $(0.040)$ \\
Controls & Yes & Yes & Yes & Yes & Yes & Yes \\
Adj. R ${ }^{2}$ & 0.026 & 0.029 & 0.101 & 0.016 & 0.211 & 0.116 \\
& & & & & & \\
Control Mean & 0.0460 & -0.0588 & 0.4356 & 0.0037 & -0.0261 & -0.0093 \\
& & & & & & \\
Departments & 984 & 993 & 994 & 991 & 965 & 992 \\
Individuals & 3,573 & 3,641 & 3,624 & 3,651 & 3,406 & 3,649 \\
\hline \hline
\end{tabular}

Notes: Dependent variable in Column (3) represents binary response to, "In the last 6 months, have you tried to figure out how much you need to save for retirement?" Dependent variables in remaining columns represent Z-scores of scaled survey responses for difficulty in finding retirement planning information, improvement in being informed about retirement planning, understanding the link between saving now and income in retirement, certainty in expected retirement income, and satisfaction with personal financial condition. Control group is the excluded category. Sample is restricted to employees present in both Period 1 and Period 2 who responded to follow-up survey. Respondents who answer "Don't know" or "Prefer not to say" were omitted. Standard errors clustered at unit of randomization (Department) with unit of stratification fixed effects. Control variables include a gender indicator variable, quadratic in age, quadratic in tenure, $\ln ($ salary), percentage change in salary, faculty indicator, and indicators for different campuses. ${ }^{*}$ Significantly different at the $10 \%$ level; ${ }^{* *}$ at the $5 \%$ level; ${ }^{* * *}$ at the $1 \%$ level. 


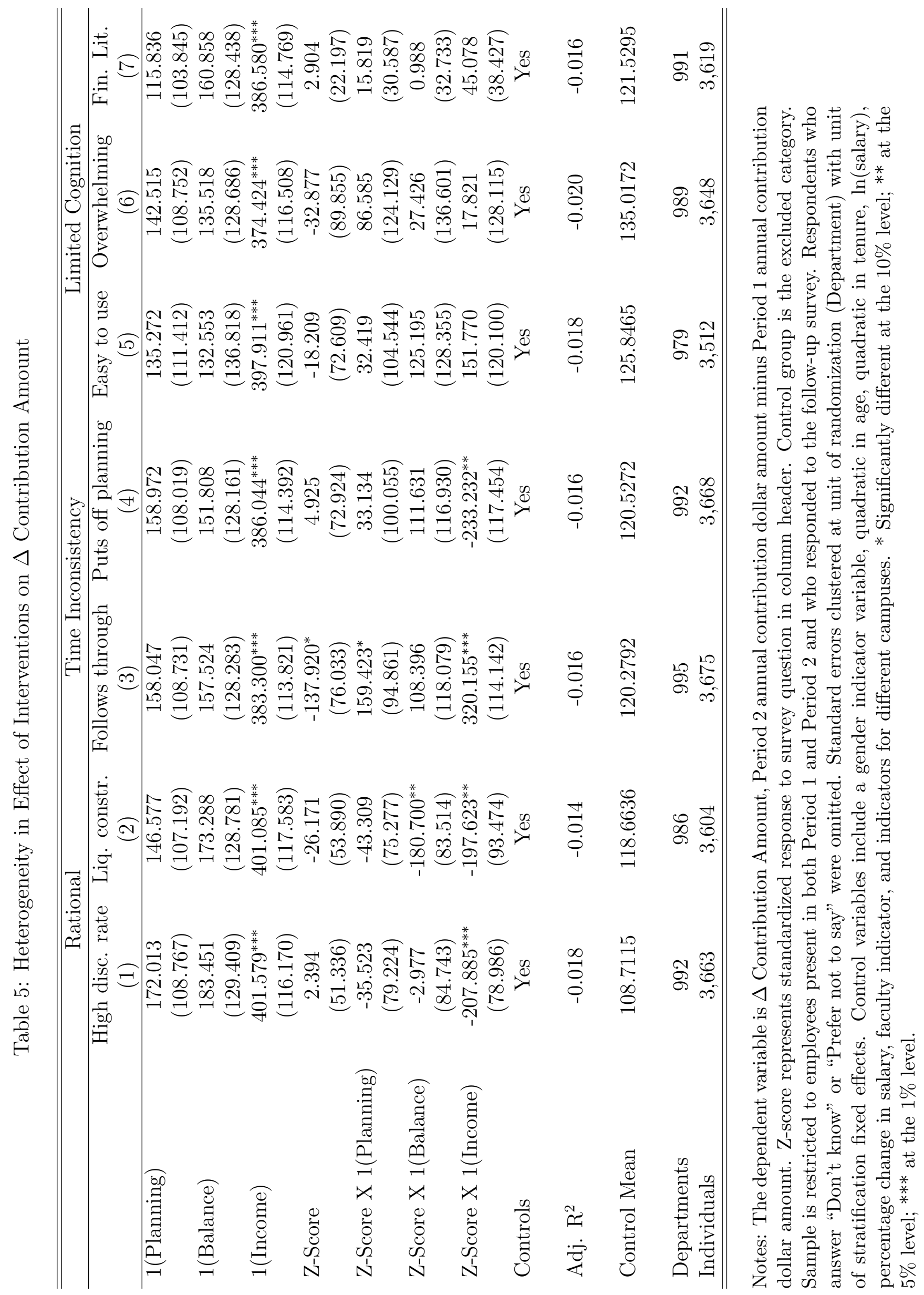


Table 6: Effect of Assumptions on $1(\Delta$ Contribution $)$

\begin{tabular}{|c|c|c|c|c|c|}
\hline & $(1)$ & $(2)$ & $(3)$ & $(4)$ & $(5)$ \\
\hline 1(Income) & $\begin{array}{l}-0.002 \\
(0.004)\end{array}$ & $\begin{array}{l}-0.002 \\
(0.004)\end{array}$ & $\begin{array}{l}-0.002 \\
(0.004)\end{array}$ & $\begin{array}{l}-0.002 \\
(0.004)\end{array}$ & $\begin{array}{l}-0.002 \\
(0.004)\end{array}$ \\
\hline $1(\operatorname{Inv}$ Ret $=5 \%)$ & $\begin{array}{c}-0.002 \\
(0.006)\end{array}$ & & & & $\begin{array}{c}0.002 \\
(0.007)\end{array}$ \\
\hline $1(\operatorname{Inv}$ Ret $=7 \%)$ & $\begin{array}{l}-0.004 \\
(0.006)\end{array}$ & & & & $\begin{array}{c}0.004 \\
(0.011)\end{array}$ \\
\hline $1($ Ret Age $=67)$ & & $\begin{array}{l}0.012^{* *} \\
(0.005)\end{array}$ & & & $\begin{array}{l}0.016^{* *} \\
(0.006)\end{array}$ \\
\hline 1(High Axes) & & & $\begin{array}{c}0.006 \\
(0.005)\end{array}$ & & $\begin{array}{c}0.016 \\
(0.012)\end{array}$ \\
\hline $\ln (\mathrm{RPM})$ & & & & $\begin{array}{c}0.005 \\
(0.006)\end{array}$ & $\begin{array}{l}-0.015 \\
(0.016)\end{array}$ \\
\hline Controls & Yes & Yes & Yes & Yes & Yes \\
\hline Adj. $R^{2}$ & 0.028 & 0.029 & 0.028 & 0.028 & 0.029 \\
\hline Balance Mean & 0.0526 & 0.0526 & 0.0526 & 0.0526 & 0.0526 \\
\hline Departments & 681 & 681 & 681 & 681 & 681 \\
\hline Individuals & 8,484 & 8,484 & 8,484 & 8,484 & 8,484 \\
\hline
\end{tabular}

Notes: Dependent variable is $\mathbf{1}(\Delta$ Contribution), which is an indicator for whether there was any change in the election between Periods 1 and 2. Sample is restricted to employees in the Income and Balance treatment groups who present in both Period 1 and Period 2. Balance group is the excluded category. Standard errors clustered at unit of randomization (Department) with unit of stratification fixed effects. Control variables include a gender indicator variable, quadratic in age, quadratic in tenure, $\ln$ (salary), percentage change in salary, faculty indicator, and indicators for different campuses. * Significantly different at the $10 \%$ level; ** at the $5 \%$ level; *** at the $1 \%$ level. 
Table 7: Effect of Assumptions on $\Delta$ Contribution Amount

\begin{tabular}{|c|c|c|c|c|c|}
\hline & (1) & $(2)$ & (3) & (4) & (5) \\
\hline 1(Income) & $\begin{array}{c}23.976 \\
(32.765)\end{array}$ & $\begin{array}{l}24.504 \\
(32.729)\end{array}$ & $\begin{array}{l}25.188 \\
(32.711)\end{array}$ & $\begin{array}{l}25.906 \\
(32.843)\end{array}$ & $\begin{array}{l}24.459 \\
(32.675)\end{array}$ \\
\hline $1(\operatorname{Inv}$ Ret $=5 \%)$ & $\begin{array}{l}19.135 \\
(53.581)\end{array}$ & & & & $\begin{array}{l}29.815 \\
(76.277)\end{array}$ \\
\hline $1(\operatorname{Inv}$ Ret $=7 \%)$ & $\begin{array}{l}-27.962 \\
(53.756)\end{array}$ & & & & $\begin{array}{c}-6.262 \\
(108.591)\end{array}$ \\
\hline $1($ Ret Age $=67)$ & & $\begin{array}{l}73.612^{*} \\
(43.478)\end{array}$ & & & $\begin{array}{c}82.884^{*} \\
(49.030)\end{array}$ \\
\hline 1(High Axes) & & & $\begin{array}{c}103.881^{* *} \\
(44.217)\end{array}$ & & $\begin{array}{c}135.058 \\
(122.515)\end{array}$ \\
\hline $\ln (\mathrm{RPM})$ & & & & $\begin{array}{l}95.017^{* *} \\
(48.376)\end{array}$ & $\begin{array}{c}-45.441 \\
(157.242)\end{array}$ \\
\hline Controls & Yes & Yes & Yes & Yes & Yes \\
\hline Adj. $R^{2}$ & -0.003 & -0.003 & -0.002 & -0.003 & -0.002 \\
\hline Balance Mean & 139.4744 & 139.4744 & 139.4744 & 139.4744 & 139.4744 \\
\hline & 681 & 681 & 681 & 681 & 681 \\
\hline Individuals & 8,484 & 8,484 & 8,484 & 8,484 & 8,484 \\
\hline
\end{tabular}

Notes: Dependent variable is $\Delta$ Contribution Amount, which is Period 2 contribution dollar amount minus Period 1 contribution dollar amount. Sample is restricted to employees in the Income and Balance treatment groups who present in both Period 1 and Period 2. Balance group is the excluded category. Standard errors clustered at unit of randomization (Department) with unit of stratification fixed effects. Control variables include a gender indicator variable, quadratic in age, quadratic in tenure, $\ln$ (salary), percentage change in salary, faculty indicator, and indicators for different campuses. * Significantly different at the $10 \%$ level; ** at the $5 \%$ level; *** at the $1 \%$ level. 
Table 8: Effects of Interventions and Assumptions on Retirement Age and Investment Return Beliefs

\begin{tabular}{ccccc}
\hline \hline & $(1)$ & $(2)$ & $(3)$ & $(4)$ \\
\hline & Exp. Ret Age & Exp. Return & Exp. Ret Age & Exp. Return \\
1 (Planning) & $0.383^{* *}$ & 0.131 & & \\
& $(0.162)$ & $(0.119)$ & & \\
1 (Balance) & 0.281 & 0.095 & & \\
& $(0.184)$ & $(0.122)$ & & \\
1 (Income) & -0.086 & 0.104 & -0.336 & 0.131 \\
& $(0.174)$ & $(0.119)$ & $(0.208)$ & $(0.134)$ \\
Inv Return(\%) & & & -0.033 & 0.038 \\
& & & $(0.061)$ & $(0.040)$ \\
1 (Ret Age=67) & & & 0.216 & 0.091 \\
& & & $0.209)$ & $(0.141)$ \\
1 (Higher axes) & & & 0.141 & 0.024 \\
& & & $(0.213)$ & $(0.135)$ \\
Controls & Yes & Yes & Yes & Yes \\
Adj. R ${ }^{2}$ & 0.090 & 0.023 & 0.077 & 0.010 \\
Control Mean & 65.6266 & 5.2896 & & \\
& & & & \\
Balance Mean & & & 66.0049 & 5.3682 \\
& & & 455 & 394 \\
Departments & 940 & 847 & 1,537 & 1,151 \\
Individuals & 3,188 & 2,440 & & \\
\hline \hline
\end{tabular}

Notes: Dependent variable is as indicated in column heading. Control group is the excluded category in Columns 1 and 2; balance group is the excluded category in Columns 3 and 4 . Sample is restricted to employees present in both Period 1 and Period 2 who responded to follow-up survey. Columns 3 and 4 restrict attention to the balance and income groups. Respondents who answer "Don't know" or "Prefer not to say" were omitted. Standard errors clustered at unit of randomization (Department) with unit of stratification fixed effects. Control variables include a gender indicator variable, quadratic in age, quadratic in tenure, $\ln$ (salary), percentage change in salary, faculty indicator, and indicators for different campuses. * Significantly different at the $10 \%$ level; $* *$ at the $5 \%$ level; *** at the $1 \%$ level. 
Figure 1: Outcome Variables by Treatment Group

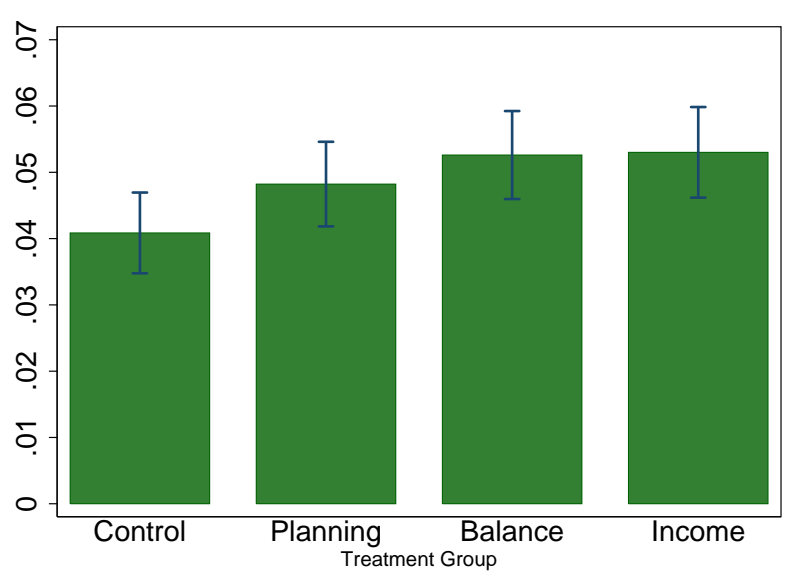

(a) $\mathbf{1}(\Delta$ Contribution $)$

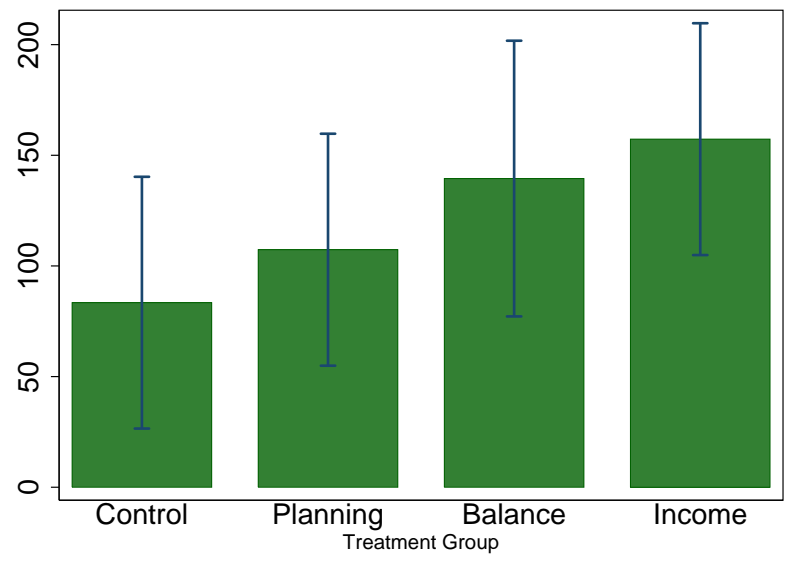

(b) $\Delta$ Contribution (Amount): Post - Pre

Notes: $\mathbf{1}(\Delta$ Contribution $)$ is an indicator for whether there was any active change in the election. $\Delta$ Contribution Amount is Period 2 contribution dollar amount minus Period 1 contribution dollar amount. Height of bar equals mean of each variable and brackets indicate $95 \%$ confidence interval. 


\section{Appendix A Proof of Proposition 1}

Proof. Using equations (3) and (1), define

$$
G\left(\theta, A_{2}^{*}\right) \equiv U^{\prime}\left(Y_{1}+A_{1}-A_{2}^{*}\right)-g(\theta) p\left(\beta R^{\theta}\right)^{k} U^{\prime}\left(g(\theta) p R^{k \theta} A_{2}^{*}\right)=0
$$

Applying the implicit function theorem reveals that:

$$
\frac{\partial A_{2}^{*}}{\partial \theta}=-\frac{\frac{\partial G}{\partial \theta}}{\frac{\partial G}{\partial C_{1}^{*}}}=-\frac{\left[p\left(\beta R^{\theta}\right)^{k}\left(g^{\prime}(\theta)+g(\theta) \ln (R) k\right)\right]\left[U^{\prime}\left(C_{2}^{*}\right)+U^{\prime \prime}\left(C_{2}^{*}\right) g(\theta) p R^{k \theta} A_{2}^{*}\right]}{U^{\prime \prime}\left(C_{1}^{*}\right)+\beta^{k}\left[g(\theta) p R^{\theta k}\right]^{2} U^{\prime \prime}\left(C_{2}^{*}\right)}
$$

The denominator is negative and the leading term of the numerator is positive. Therefore, the sign of $\frac{\partial A_{2}^{*}}{\partial \theta}$ is the same as that of the bracketed term in the numerator, which follows the sign of $\epsilon(\theta)-1$. 


\section{Appendix B Comparison to National Population}

We explore how the study sample compares to the national population. Table B-1 compares available demographic characteristics of the full administrative sample and the follow-up survey subsample to the Financial Capability Study's state-by-state, nationally-representative sample sponsored by FINRA. ${ }^{22}$ We impose sample restrictions on the FINRA national sample, including working age (18 to 64), employed, and covered by pension plan, to clarify the extent to which these restriction explain observed differences between the FINRA and study samples.

The full sample of University of Minnesota employees is 56 percent female, while the follow-up survey subsample is 63 percent female (Table B-1). In comparison, the FINRA national sample is only 48.7 percent female. When we restrict the FINRA sample to the same ages (18-64) as the study sample, which constitutes 84.8 percent of the national population, the percent female in FINRA increases to 49.8 percent. When we restrict the national sample to employed workers, this leaves a subsample that represents 43.8 percent of the national population and is 54.6 percent female. This reveals that the fraction of the study sample that is female is similar to the fraction of employed Americans who are female. Finally, when we add the employer-provided pension plan restriction the FINRA national, which leaves only 28.7 percent of the original FINRA sample, the fraction female remains stable ( 54.5 percent) and is comparable to the study sample. Comparing the full study sample to the restricted FINRA sample also reveals that the age profiles are very similar.

The follow-up survey sample, however, is substantially more likely to be white than the most comparable national subsample (90 versus 68 percent). The follow-up survey sample is also somewhat more likely to be married (73 versus 64 percent), much more likely to have a post-graduate degree (52 versus 15 percent), and less liquidity constrained. While the fractions reporting having tried to figure how much savings is needed for retirement are similar, the questions ask about different reference periods. In the study survey, 45.2 percent

\footnotetext{
${ }^{22}$ FINRA is the Financial Industry Regulatory Authority.
} 
reporting having done this in the last six months, since the Period 1 data pull. In contrast, the national sample is asked to report having done this ever.

We included select FINRA questions on our follow-up survey to facilitate comparbility between the follow-up survey sample and the FINRA respodents in terms of financial literacy (Table B-2). The results suggest that, in comparison to the national subsamples, the study's follow-up survey subsample is more financially satisfied, more likely to keep up with economic and financial news, higher self-assessed financial literacy, higher score on the financial literacy quiz, and is slightly more willing to take risks. However, they report being about equally good at day-to-day financial matters and equally in agreement with the statement, "I'm pretty good at math." 


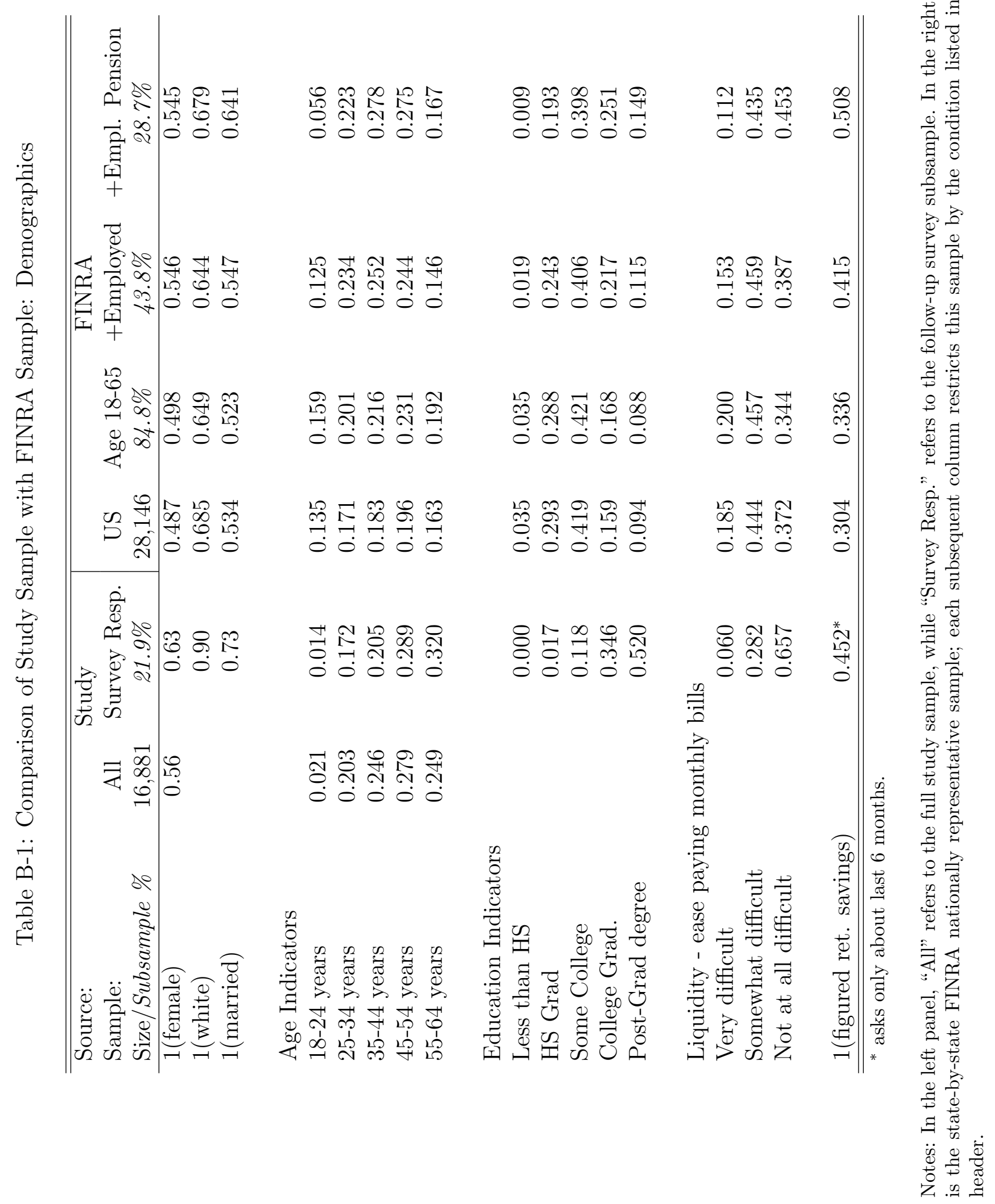




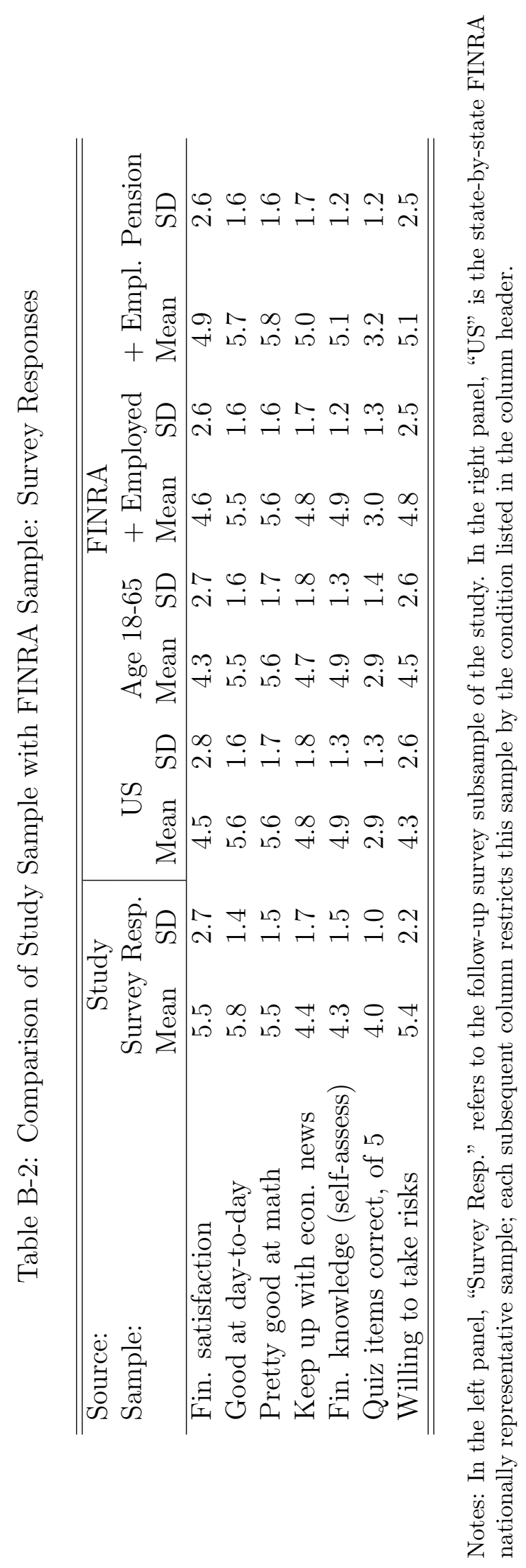


Appendix C Intervention Materials 


\section{Figure C-1: Example Brochure: Page 1}

\section{Am I on Target to Meet My Retirement Goals?}

\section{Retirement Savings at the University of Minnesota}

What sources of income will be available to me in retirement?

- Most University employees participate in mandatory retirement plans.

o The Minnesota State Retirement System provides a traditional pension to most civil service and non-faculty bargaining unit employees.

o The Faculty Retirement Plan is a defined contribution plan to which most faculty and academic professionals and administrators (P\&A employees) contribute.

- Most employees are eligible to participate in Voluntary Retirement Plans, which allow up to $\$ 16,500$ of pre-tax contributions per year. The two types of Voluntary Retirement Plans are the

o Optional Retirement Plan (ORP) and

o Section 457 Deferred Compensation Plan.

- Substantially all University employees also participate in the federal Social Security system.

\section{How much retirement income will I want?}

People typically want retirement income to be between $75 \%$ and $90 \%$ of their expected income prior to retirement, depending on their desired lifestyle.

My goal is: \$ per year.

\section{Am I on target to meet my goals?}

Social Security and mandatory retirement plans provide some, but often not all, of the retirement income desired. Consult plan statements, Social Security benefit statements, or advisors for estimates of retirement income from these sources.

From Social Security and my mandatory retirement plan, I expect \$ per year.

\section{What else can I do?}

Voluntary Retirement Plans can help fill any gap. Nearly 5,000 University of Minnesota employees take advantage of these additional tax-advantaged savings opportunities. 


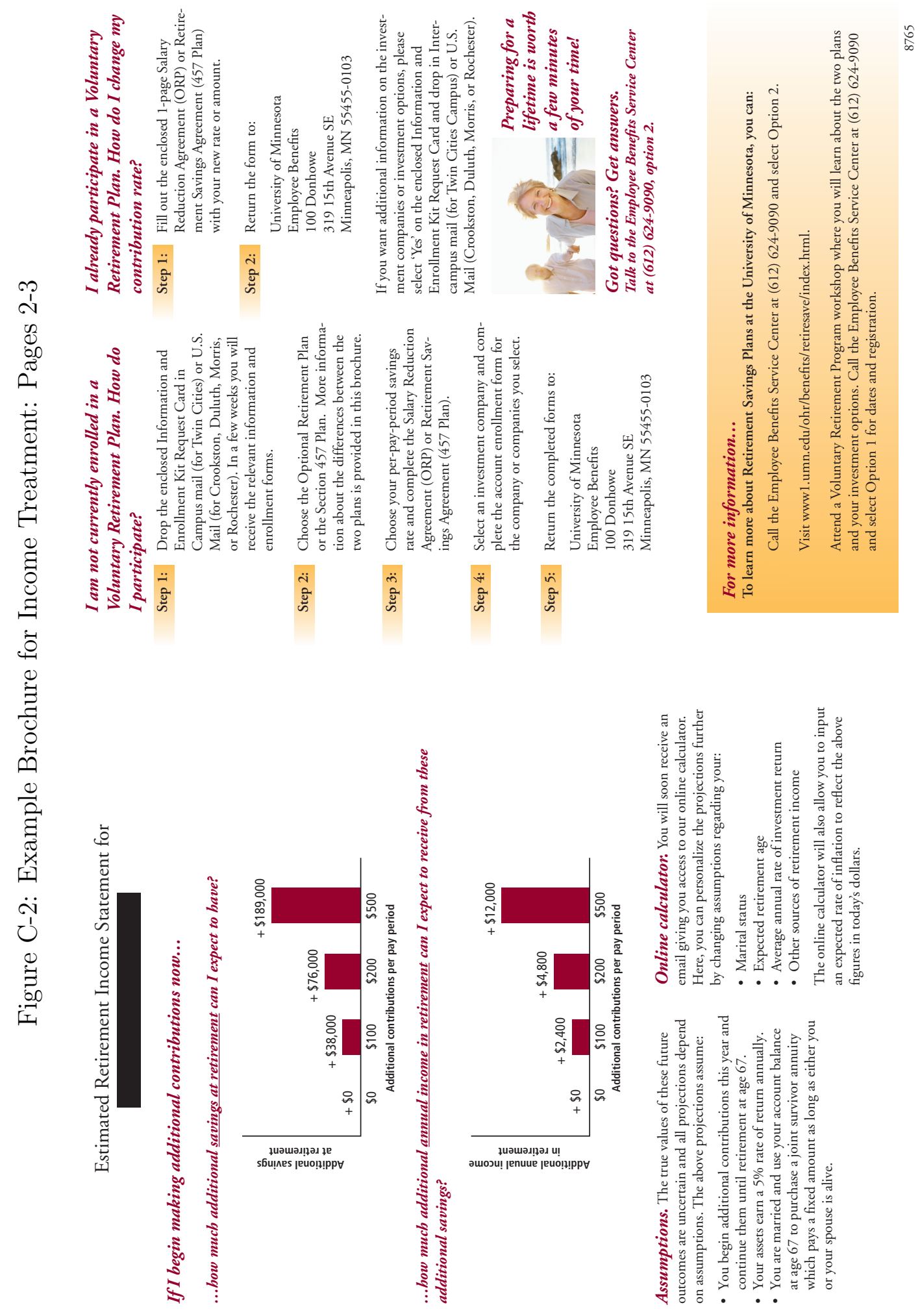




\section{Figure C-3: Example Brochure Final Page}

\section{Comparing the Optional Retirement and 457 Plans}

Pension law simplified 457 Plans to bring them more in line with qualified retirement plans like the Optional Retirement Plan. However, differences still exist. To help you understand these differences so you can make the most of your retirement saving opportunities - review the chart below.

Optional Retirement Plan

In-service distributions while employed

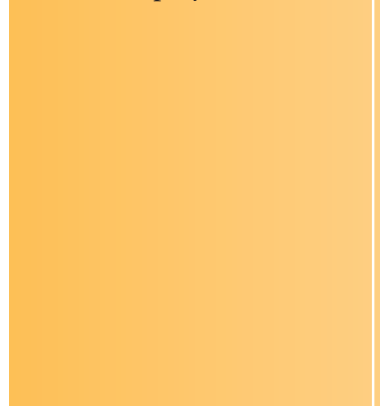

Annual contribution
limits

Catch-up contributions

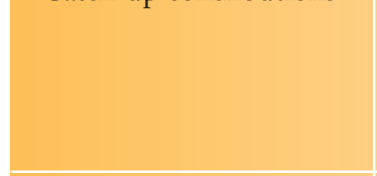

Loans

Investment options

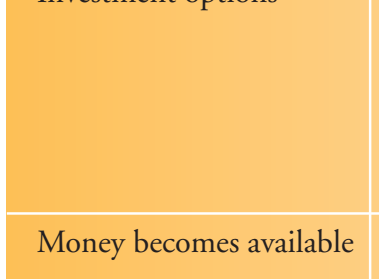

Money becomes available
- Distributions may be made for any financial hardship, in cluding college education (at the University's discretion)

- Available after age 591/2 for any reason

\section{$\$ 200$ Minimum} $\$ 16,500$ Maximum

May be made beginning at age 50

Up to 50 percent of your balance may be available to you as a loan, to a maximum of $\$ 50,000$

Range from aggressive growth mutual funds to conservative interest-bearing accounts with Securian Retirement, Fidelity, Vanguard, and DWS Scudder Investments

The earlier of termination of employment or reaching age $591 / 2$

\section{Plan}

Distributions are only available for unforeseeable emergencies (at the University's discretion) or if:

- Your balance does not exceed $\$ 5,000$

- There have been no previous in-service distributions

- You've made no contributions in the previous two years

- You elect such a distribution

No minimum $\$ 16,500$ Maximum

In the three years prior to the year in which you turn age 65 , you may contribute up to a maximum of twice that year's maximum contribution amount

Not allowed

Range from aggressive growth mutual funds to conservative interest-bearing accounts with Securian Retirement, Fidelity, and Vanguard

The later of termination or the calendar year in which you attain age $701 / 2$ 


\section{Figure C-4: Online Customization Tool Screenshot: Income Treatment}

LIDA Calculator Proto V4.0

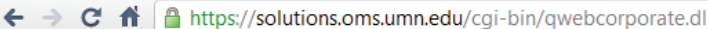

\section{Retirement Income Online Customization Tool}

Fill in your characteristics and assumptions below.

Then hit the Calculate button at the bottom of the page.

If I begin making additional contributions now...

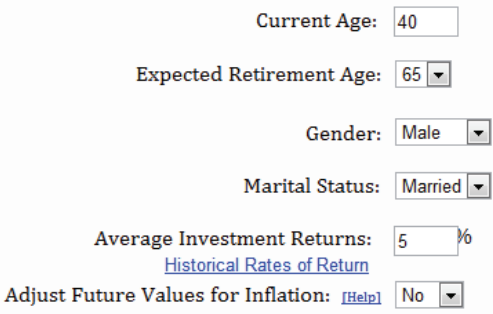

\section{Current Contributions per Pay Period}

U of M Voluntary Retirement Plans: [Help] 300

Other retirement savings accounts: [Help] 100

\section{Current Account Balances}

U of M Voluntary Retirement Plans: [Help] 100000

Other retirement savings accounts: [Help] 150000

Estimated Annual Income at Retirement Age from Other Sources

Annual Defined Benefit Income: [Help] 0

Annual Social Security Income: [Help] 10000

Social Security estimation calculator

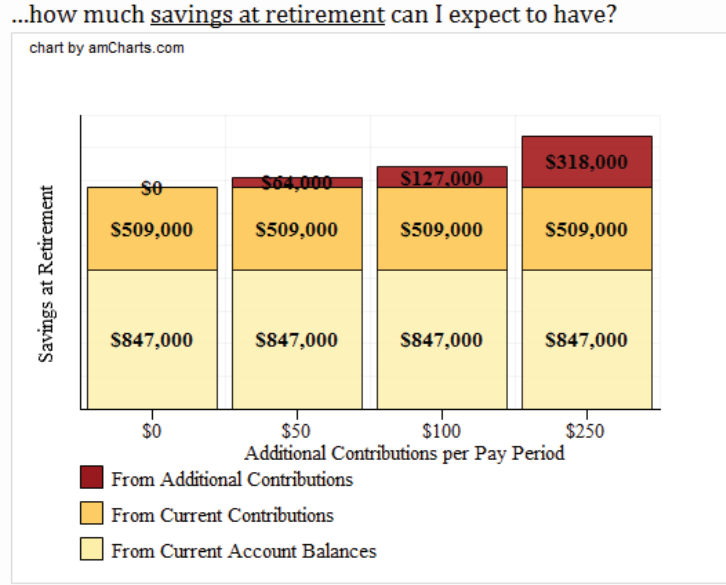

...how much annual income in retirement can I expect to receive from these savings?

chart by amcharts.com

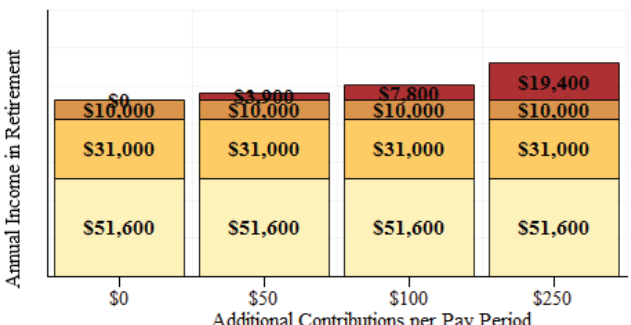

From Additional Contributions

$\square$ From Social Security and Defined Benefit Plans

$\square$ From Current Contributions

$\square$ From Current Account Balances

Assumptions. The true values of these future outcomes are uncertain and all projections depend on assumptions. The above projections assume:

- You begin additional contributions this year and continue them until you retire at age 65

- Your assets earn a 5\% rate of return annually.

- Your projections have not been adjusted for future inflation. This is equivalent to assuming future inflation is $0 \%$ per year.

- You are married and use your account balance at age 65 to purchase a joint survivor annuity which pays a fixed amount as long as either you or your spouse is alive. 


\section{Appendix D Balance across Treatment Groups: Full and Follow-up Survey Samples}

Observable characteristics by treatment group are shown for the full administrative sample in Table D-1. Each characteristic was regessed on treatment group indicators with the mean of the characteristic for the control group shown in a row below. We report the Fstatistic for the joint test of the hypothesis that all coeficients on the planning, balance and income group indicator variables are zero and report the p-value of the test at the bottom of the table. The shaded columns represent characteristics which were explicitly balanced across treatment groups in the randomization procedure. The table shows that there are very few statistically significant differences in observable characteristics across treatment groups. The only characteristic that differs significantly across the different groups is gender, with a statistically higher percentage of women in the income group. For the remaining characteristics, we fail to reject the null hypothesis that there are differences across the four experimental groups.

In terms of the follow-up survey sample, Table D-2 presents evidence on what factors influence survey response by regressing a dummy variable for survey response on treatment group and incentive group indicators. Column 1 shows that being assigned into one of the three groups sent printed materials significantly reduced the likelihood of response: the response rate was 24 percent in the control group, and 2-3 percentage points lower in the planning, balance, and income groups. These estimates suggest that the reduction in survey response was due to a general hassle factor from receiving repeated communication from the researchers rather than a specific piece of information contained in the balance or income group mailings. Column 2 shows that the small $\$ 2$ non-conditional incentive sent at the outset of the experiment led to a statistically significant increase in response rates, and Column 3 shows that the effect of the incentive on response rates did not significantly differ 
across treatment groups. ${ }^{23}$

We next examine the demographic characteristics of the survey respondents, how they differ from our full administrative sample, and whether the differences in response rates across treatment groups led to observable differences across treatment groups in our survey subsample. Table D-3 shows the results of regressing several observable characteristics on treatment group dummies for the survey subsample. As in Table D-1, we report the mean of the characteristic for the control group and the p-value for the joint test of the hypothesis that all coeficients on the planning, balance and income group indicator variables are zero at the bottom of the table.

Compared to Table D-1, our survey subsample is more likely to be female, has a greater number of faculty, and are more likely to be VRP participants. However, there are very few instances where observable characteristics differ significantly across treatment groups within the survey subsample. The reported p-values are generally higher than conventional levels of significance, with the exception of that for age, where the respondents in the income group are approximately one year older than respondents in the control group. Table D-4 shows the treatment effects of our administrative outcomes in our survey subsample. The estimated treatment effects are larger in magnitude relative to our full administrative sample.

Together, this evidence indicates that survey responders are not an entirely representative sample of our population, as there are some differences in observable characteristics between survey responders and the entire sample, and treatment effects are larger. However, the results in Table D-3 suggest that the differential response rate across treatment groups did not create large imbalances in observable characteristics across treatment groups within the survey subsample. Assuming that the data are missing at random conditional on observables, there are still insights to be gained from the richer set of information available from survey responders.

\footnotetext{
${ }^{23}$ The incentive had a substantial effect on survey response despite the fact that it was provided approximately four months prior to the survey.
} 


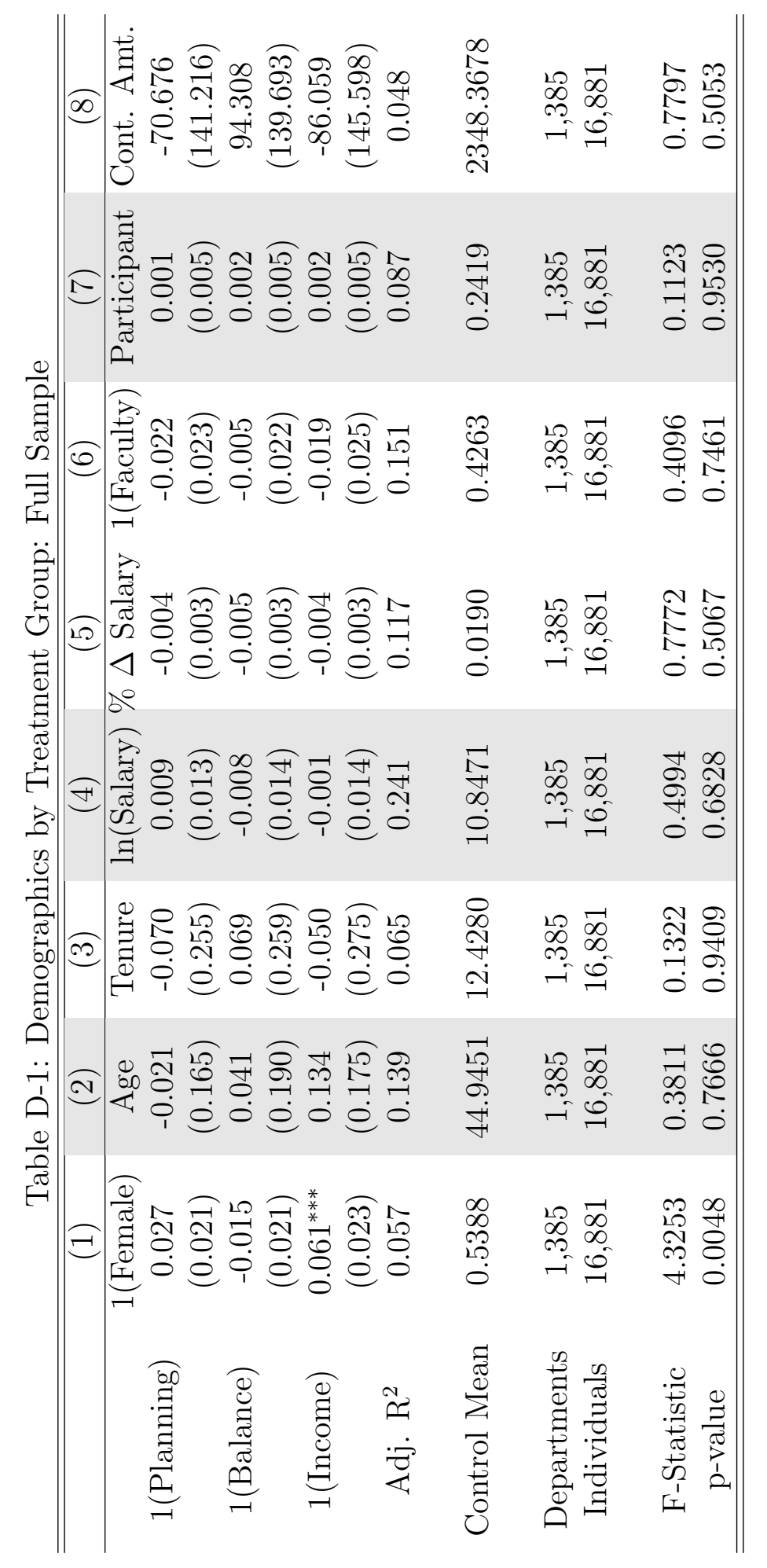

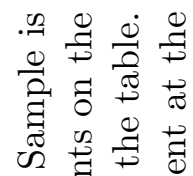

됴웜ㅇ

.류 형

김웡

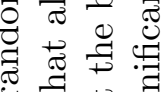

$\exists \pm$.

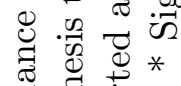

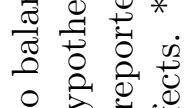

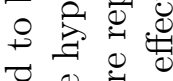

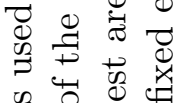

y

范要

뭉

过焉焉

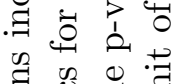

泀. 焗

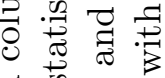
导 जึ 규 종 式 궁

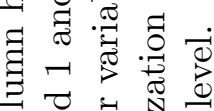

궁 훙

궁 륭

ㄴ. 금

퓽

웡혀

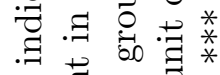

๘

음

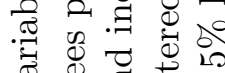

హె

节

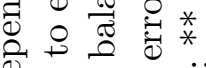

बे

i.

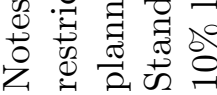


Table D-2: Survey Response by Treatment Group and Incentives

\begin{tabular}{cccc}
\hline \hline & $(1)$ & $(2)$ & $(3)$ \\
\hline 1 (Planning) & $-0.024^{* *}$ & & $-0.021^{*}$ \\
& $(0.010)$ & $(0.011)$ \\
1 (Balance) & $-0.039^{* * *}$ & $-0.042^{* * *}$ \\
1 (Income) & $(0.010)$ & $(0.011)$ \\
& $-0.028^{* * *}$ & $-0.030^{* * *}$ \\
1(Incentive) & $(0.010)$ & & $(0.011)$ \\
& & $0.090^{* * *}$ & $0.083^{* * *}$ \\
1 (Incentive) X 1(Planning) & & $(0.013)$ & $(0.029)$ \\
& & & -0.032 \\
1 (Incentive) X 1(Balance) & & & $(0.039)$ \\
& & & 0.006 \\
1 (Incentive) X 1(Income) & & & $0.038)$ \\
& & & 0.054 \\
Controls & Yes & Yes & Yes \\
Adj. R & & & $0.039)$ \\
& 0.043 & 0.048 & 0.049 \\
Control Mean & & & \\
& 0.2402 & 0.2489 & 0.2489 \\
Departments & 1,385 & 1,046 & 1,046 \\
Individuals & 16,881 & 13,667 & 13,667 \\
\hline \hline
\end{tabular}

Notes: Dependent variable is indicator variable for survey responder. Control group is the excluded category. 1(Incentive) is indicator variable for receipt of non-conditional $\$ 2$ incentive in beginning of study. Sample is restricted to employees present in both Period 1 and Period 2. Columns 2 and 3 restrict attention to the Twin Cities campus because only that campus was eligible to receive the non-conditional incentive. Standard errors clustered at unit of randomization (Department) with unit of stratification fixed effects. Control variables include a gender indicator variable, quadratic in age, quadratic in tenure, $\ln$ (salary), percentage change in salary, faculty indicator, and indicators for different campuses. ${ }^{*}$ Significantly different at the $10 \%$ level; $* *$ at the $5 \%$ level; *** at the $1 \%$ level. 


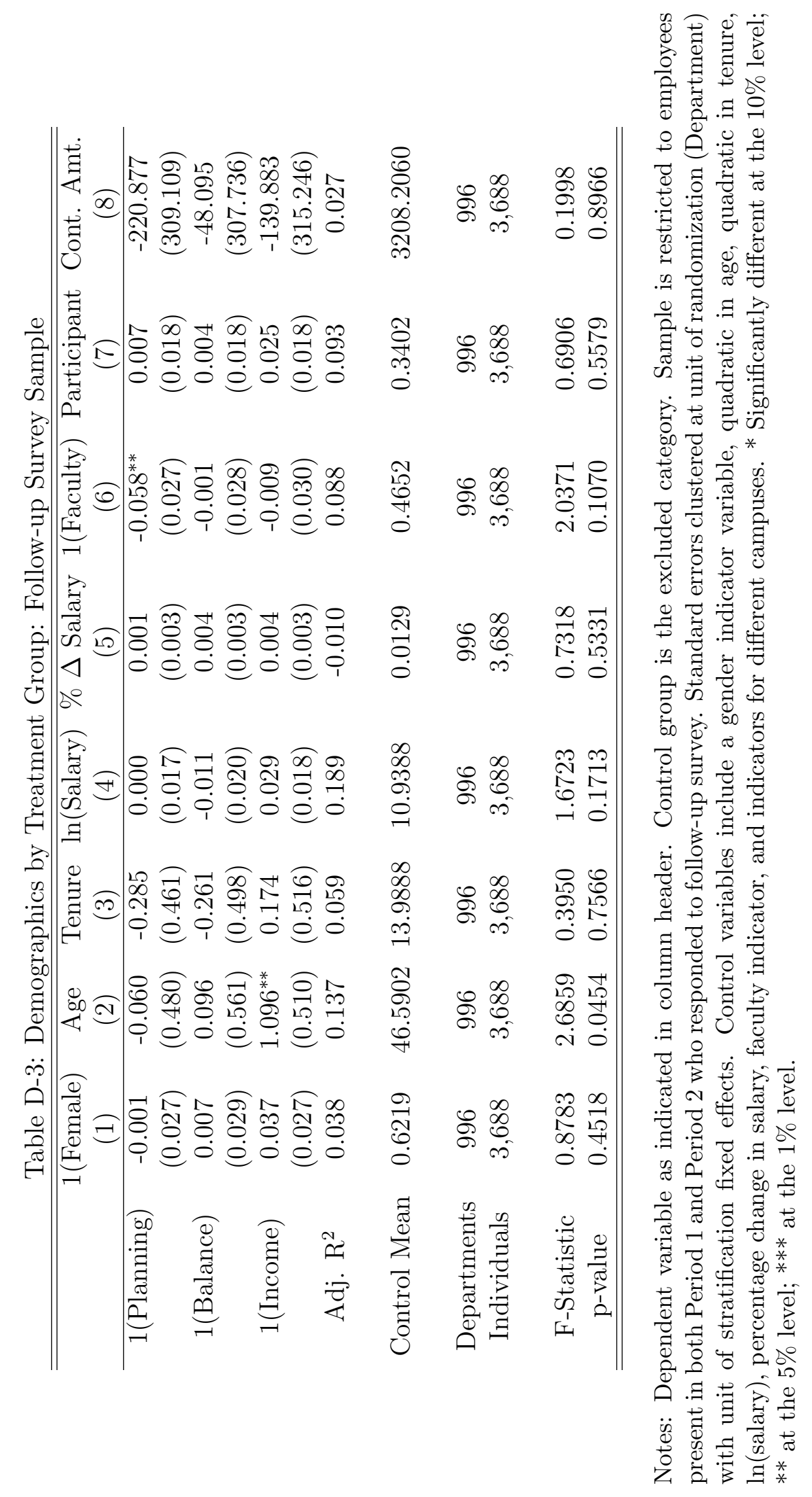


Table D-4: Effect of Interventions: Follow-Up Survey Subample

\begin{tabular}{lcccccc}
\hline \hline Outcome: & \multicolumn{3}{c}{$1(\Delta$ Contrib. } & \multicolumn{3}{c}{$\Delta$ Contrib. Amt. } \\
& $(1)$ & $(2)$ & $(3)$ & $(4)$ & $(5)$ & $(6)$ \\
\hline 1(Planning) & $0.028^{* *}$ & $0.034^{* * *}$ & $0.032^{* * *}$ & 92.410 & 146.974 & 156.591 \\
& $(0.013)$ & $(0.012)$ & $(0.012)$ & $(94.572)$ & $(107.036)$ & $(108.575)$ \\
1 (Balance) & $0.042^{* * *}$ & $0.051^{* * *}$ & $0.051^{* * *}$ & 101.140 & 145.999 & 154.868 \\
& $(0.014)$ & $(0.013)$ & $(0.013)$ & $(109.785)$ & $(127.414)$ & $(128.151)$ \\
1 (Income) & $0.050^{* * *}$ & $0.058^{* * *}$ & $0.054^{* * *}$ & $326.426^{* * *}$ & $391.536^{* * *}$ & $385.563^{* * *}$ \\
& $(0.012)$ & $(0.012)$ & $(0.012)$ & $(97.782)$ & $(114.756)$ & $(114.828)$ \\
& & & & & & \\
Quad FEs & No & Yes & Yes & No & Yes & Yes \\
Controls & No & No & Yes & No & No & Yes \\
Adj. R & 0.004 & 0.013 & 0.018 & 0.002 & -0.019 & -0.017 \\
& & & & & & \\
Control Mean & 0.0625 & 0.0625 & 0.0625 & 119.7863 & 119.7863 & 119.7863 \\
& & & & & & \\
Departments & 996 & 996 & 996 & 996 & 996 & 996 \\
Individuals & 3,688 & 3,688 & 3,688 & 3,688 & 3,688 & 3,688 \\
\hline \hline
\end{tabular}

Notes:Notes: $\mathbf{1}(\Delta$ Contrib. $)$ is an indicator for whether there was any change in the election and $\Delta$ Contrib. Amt. is Period 2 contribution dollar amount minus Period 1 contribution dollar amount. Control group is the excluded category. Sample is restricted to employees present in both Period 1 and Period 2 and who responded to the follow-up survey. Standard errors clustered at unit of randomization (Department) with unit of stratification fixed effects. Control variables in columns (3) and (6) include a gender indicator variable, quadratic in age, quadratic in tenure, $\ln ($ salary), percentage change in salary, faculty indicator, and indicators for different campuses. * Significantly different at the $10 \%$ level; ${ }^{* *}$ at the $5 \%$ level; $* * *$ at the $1 \%$ level. 
Appendix E Distributions of Survey Item Responses 


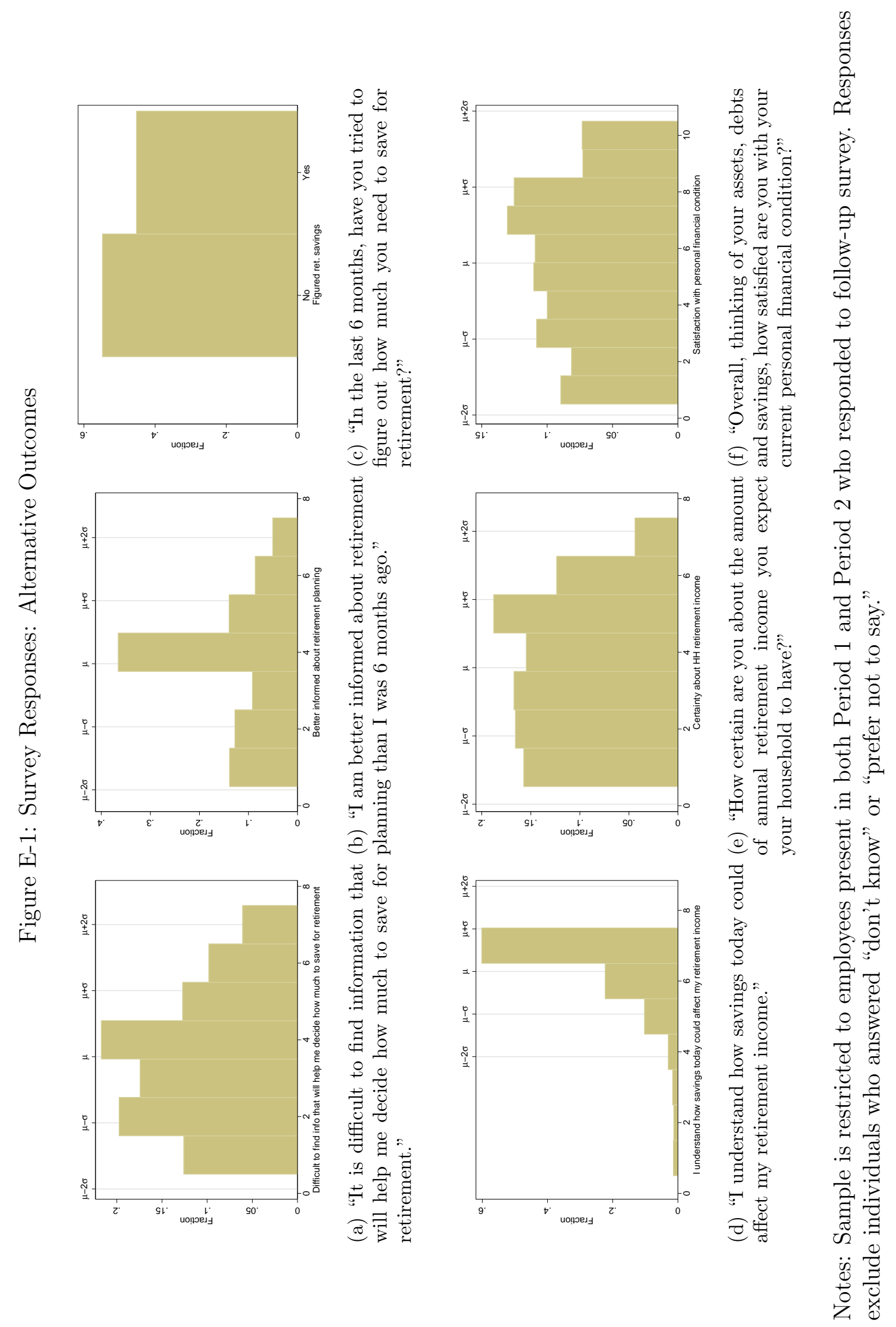



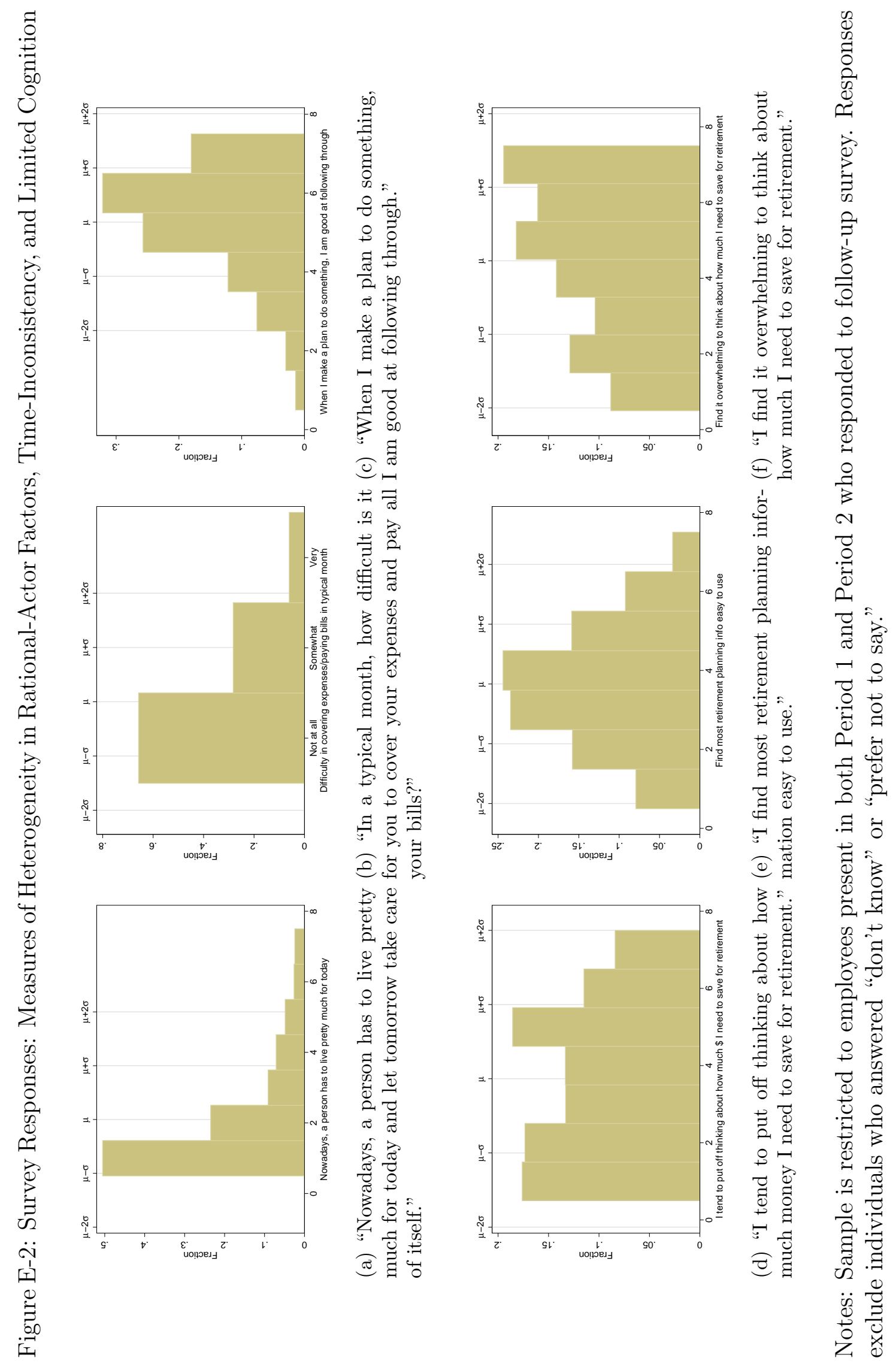

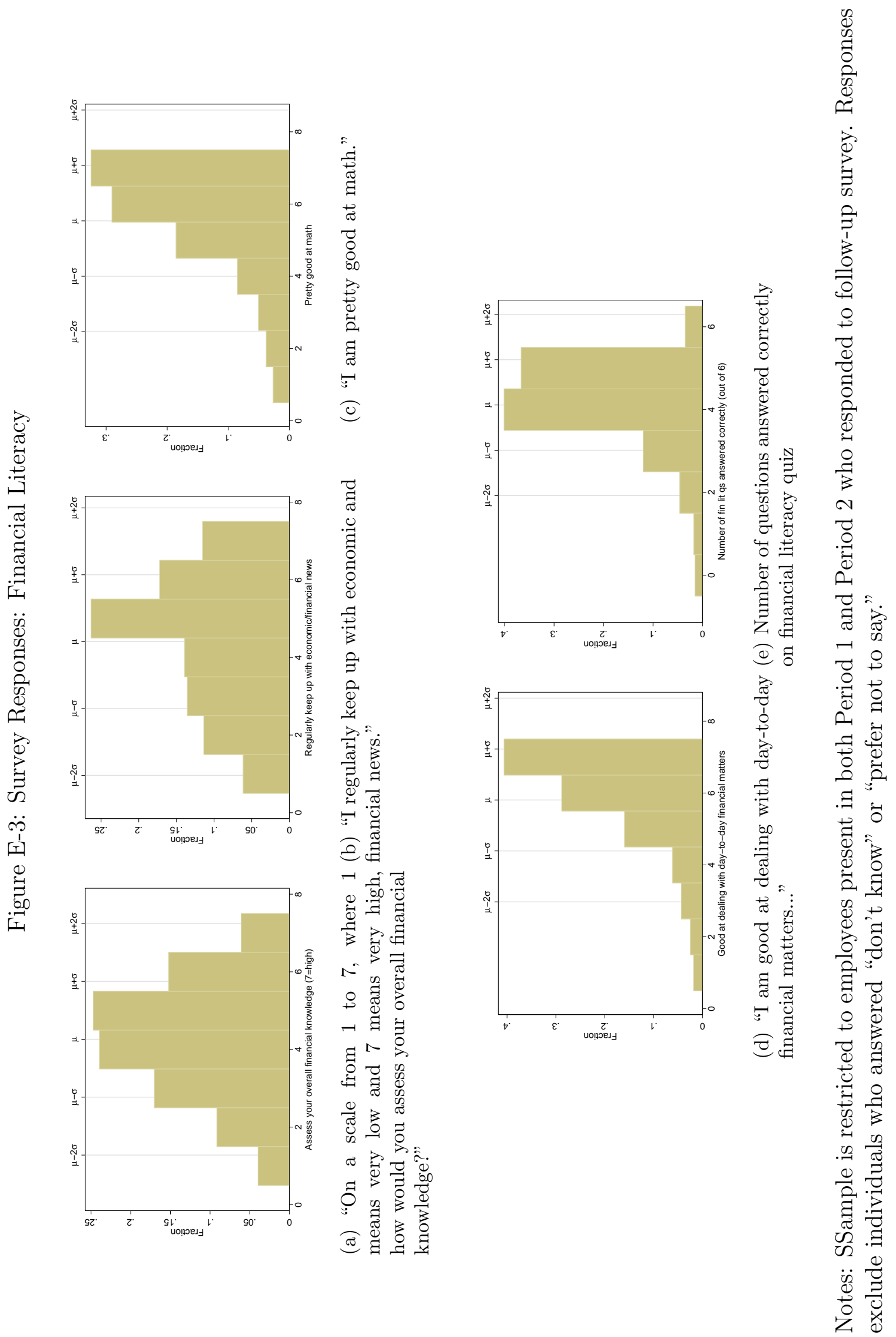
Figure E-4: Survey Responses: Retirement Age and Investment Return Beliefs

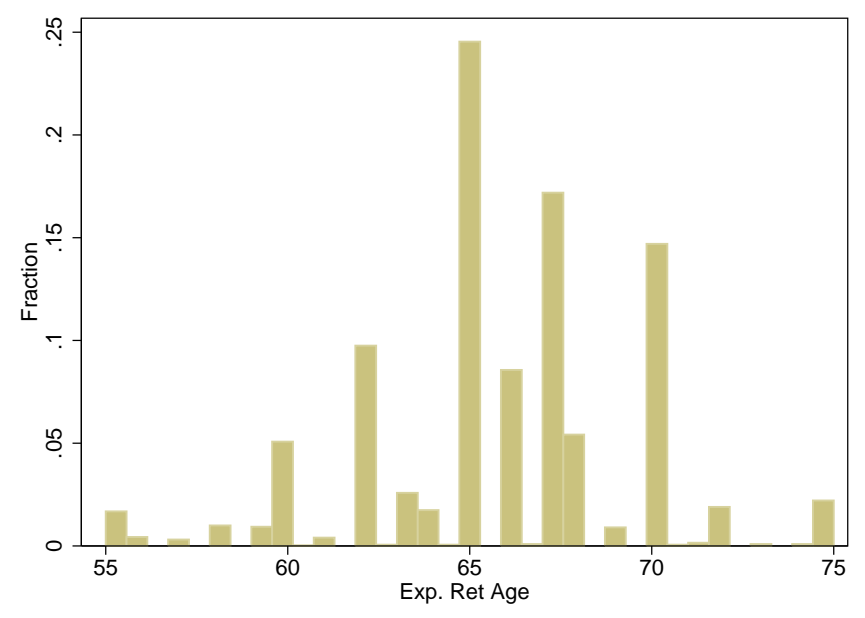

(a) Expected Retirement Age

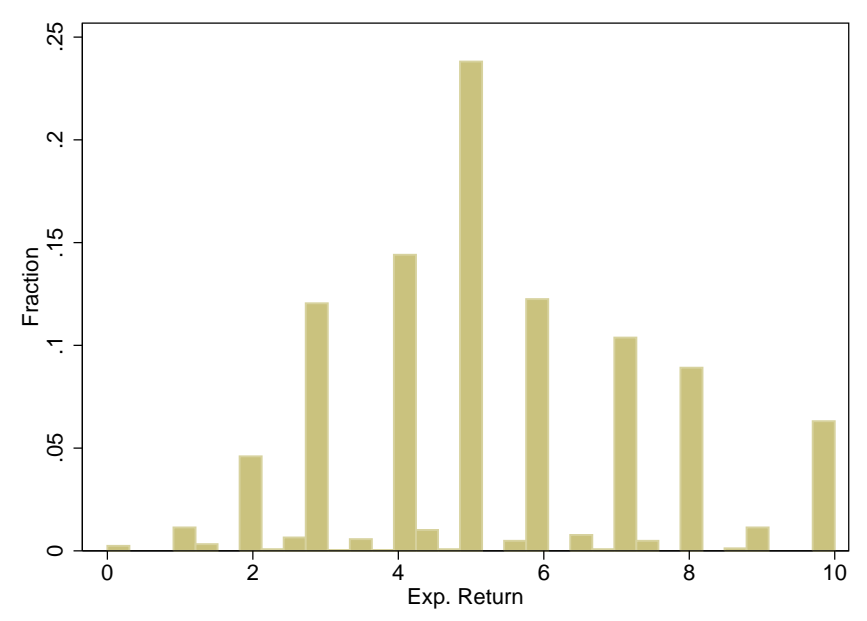

(b) Expected Rate of Return

Notes: Sample is restricted to employees present in both Period 1 and Period 2 who responded to follow-up survey. Responses exclude individuals who answered "don't know" or "prefer not to say." 


\section{Appendix F Financial Literacy Questions}

The following questions comprise the financial literacy quiz provided to survey respondents. ${ }^{24}$ Correct answers are marked in bold.

1. Imagine that the interest rate on your savings account was $1 \%$ per year and inflation was $2 \%$ per year. After 1 year, how much would you be able to buy with the money in this account?
(a) More than today
(b) Exactly the same
(c) Less than today
(d) Don't know
(e) Prefer not to say

2. Do you think the following statement is true or false? "Buying a single company stock usually provides a safer return than a stock mutual fund."
(a) True
(b) False
(c) Don't know
(d) Prefer not to say

3. Suppose you had $\$ 100$ in a savings account and the interest rate was $2 \%$ per year. After 5 years, how much do you think you would have in the account if you left the money to grow:
(a) More than $\$ 102$
(b) Exactly $\$ 102$
(c) Less than $\$ 102$
(d) Don't know
(e) Prefer not to say

4. If interest rates rise, what will typically happen to bond prices?
(a) They will rise
(b) They will fall
(c) They will stay the same
(d) There is no relationship between bond prices and the interest rate
(e) Don't know

\footnotetext{
${ }^{24}$ Questions taken from Lusardi and Mitchell (2007).
} 
(f) Prefer not to say

5. Do you think the following statement is true or false? "A 15-year mortgage typically requires higher monthly payments than a 30-year mortgage, but the total interest paid over the life of the loan will be less."
(a) True
(b) False
(c) Don't know
(d) Prefer not to say

6. Let's say you have $\$ 200$ in a savings account. The account earns 10 percent interest per year. How much would you have in the account at the end of two years? [open-ended; correct answer $=\$ 242]$ 